\title{
Quantifying transport into the Arctic lowermost stratosphere
}

\author{
A. Werner ${ }^{1, *}$, C. M. Volk ${ }^{1, * *}$, E. V. Ivanova ${ }^{1}$, T. Wetter ${ }^{1, *}$, C. Schiller ${ }^{2}$, H. Schlager ${ }^{3}$, and P. Konopka ${ }^{2}$ \\ ${ }^{1}$ Institute for Atmospheric and Environmental Sciences, University of Frankfurt, Germany \\ ${ }^{2}$ Institute of Chemistry and Dynamics of the Geosphere, Research Center Jülich, Germany \\ ${ }^{3}$ Deutsches Zentrum für Luft und Raumfahrt, Institute of Atmospheric Physics, Oberpfaffenhofen, Germany \\ *now at: German Meteorological Service, DWD, Germany \\ ** now at: Department of Physics, University of Wuppertal, Germany
}

Received: 27 October 2008 - Published in Atmos. Chem. Phys. Discuss.: 15 January 2009

Revised: 19 November 2010 - Accepted: 25 November 2010 - Published: 8 December 2010

\begin{abstract}
In the Arctic winter 2003, in-situ measurements of the long-lived trace gases $\mathrm{N}_{2} \mathrm{O}, \mathrm{CFC}-11\left(\mathrm{CCl}_{3} \mathrm{~F}\right), \mathrm{H}-$ $1211\left(\mathrm{CBrClF}_{2}\right), \mathrm{CH}_{4}, \mathrm{O}_{3}$ and $\mathrm{H}_{2} \mathrm{O}$ have been performed on board the high-altitude aircraft M55 Geophysica. The data are presented and used to study transport into the lowermost stratosphere (LMS). The LMS can be regarded as a mixture of fractions of air originating in (i) the troposphere, (ii) the extra-vortex stratosphere above $400 \mathrm{~K}$ and (iii) the Arctic vortex above $400 \mathrm{~K}$. These fractions are determined using a simple mass balance calculation. The analysis exhibits a strong tropospheric influence of $50 \% \pm 15 \%$ or more in the lowest $20 \mathrm{~K}$ of the high-latitude LMS. Above this region the LMS is dominated by air masses having descended from above $400 \mathrm{~K}$. Below the Arctic vortex region at potential temperatures above $360 \mathrm{~K}$, air in the LMS is a mixture of extra-vortex stratospheric and vortex air masses. The vortex fraction increases from about $40 \% \pm 15 \%$ at $360 \mathrm{~K}$ to $100 \%$ at $400 \mathrm{~K}$ for equivalent latitudes $>70^{\circ} \mathrm{N}$. This influence of air masses descending through the bottom of the polar vortex increases over the course of the winter. By the end of winter a significant fraction of $30 \% \pm 10 \%$ vortex air in the LMS is found even at an equivalent latitude of $40^{\circ} \mathrm{N}$. Since the chemical and dynamical history of vortex air is distinct from that of mid-latitude stratospheric air masses, this study implies that the composition of the mid- to high-latitude LMS during late winter and spring is significantly influenced by the Arctic vortex.
\end{abstract}

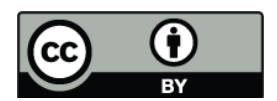

Correspondence to: A. Werner (anja.werner@dwd.de)

\section{Introduction}

Regarding the transport of trace gases, the so-called lowermost stratosphere (LMS) is a crucial region as the troposphere and the stratosphere directly interact and air masses from both regions are mixed. It is the lowest part of the stratosphere between the tropopause and the $380 \mathrm{~K}$ isentrope. Tropospheric air can enter this region directly via transport across the extra-tropical tropopause, whereas stratospheric air descends across the $380 \mathrm{~K}$ isentrope via the mean meridional circulation (Holton et al., 1995). Stratospheretroposphere exchange (STE) controls the chemical composition of the LMS as well as of the tropopause region and thus has an important effect on the radiative and chemical balance (Pan et al., 1997) of these regions and the climate system (Haynes and Sheperd, 2001).

A distinction must be made between STE processes in the tropics and extra-tropics. In the tropics, air is transported to the upper troposphere via the Hadley circulation and ascends further into the stratosphere by transport processes connected to the Brewer-Dobson circulation (Holton et al., 1995; Brewer, 1949). The main direction of this transport is from the troposphere to the stratosphere. Nevertheless, transport from the stratosphere to the troposphere can happen episodically by breaking Kelvin waves (Fujiwara et al., 1998), in tropical cyclones (Baray et al., 1999) or in the vicinity of the subtropical jet (Zachariasse et al., 2001).

With regard to the composition of the LMS, transport processes across the extra-tropical tropopause are of greatest importance. This cross-tropopause transport takes place in adiabatic/isentropic and diabatic transport processes. It occurs in both directions and includes stratosphereto-troposphere transport (STT) as well as troposphere-tostratosphere transport (TST). 
Since the high PV gradient at the tropopause usually hinders transport across the tropopause, exchange mainly happens in regions where the tropopause is distorted or interrupted. Bi-directional STE is observed in tropopause folding events (Danielsen, 1968; Shapiro, 1980) which are connected to the polar and subtropical jet regions (Dethof et al., 2000), strong baroclinic instabilities and cyclogenesis. Sprenger et al. (2003) indicated that tropopause folding is the key feature for cross-tropopause transport in the subtropics.

Further, STE can occur in the process of streamer formation (Appenzeller and Davies, 1996), in cut-off low systems and their further development (Wirth et al., 1997). Vaughan and Timmis (1998) concluded that, associated with a streamer formation, tropospheric air was transported quasiisentropically into the LMS between $360 \mathrm{~K}$ and $390 \mathrm{~K}$.

A highly important process to provide strong STE in the mid latitudes is assumed to be connected to warm conveyor belts (Stohl, 2001; Wernli and Bourqui, 2002), i.e. moist airstreams ahead of the cold fronts of extra-tropical cyclones. Diabatic heating by latent heat release (Wernli and Davies, 1997) leads to rising of air masses and a fast transfer (few days) of low tropospheric air masses into the stratosphere. This deep TST (Wernli and Bourqui, 2002) is confined to the mid-latitude regions of baroclinic wave activity. STE has been also observed in radiative (Zierl and Wirth, 1997) or convective processes (Poulida et al., 1996; Fromm et al., 2006). The latter provide very fast transport of tracers from the ground to the stratosphere. However, their relative importance has not been quantified yet and in the winter season there will be only weak convective activity.

STE processes are episodically occurring events, associated with synoptic and mesoscale processes mentioned above. The diabatic descent of stratospheric air from the overworld into the LMS is present all year long but is strongest during winter to spring time, when planetary wave activity is strongest (Holton et al., 1995). Due to the vertical stability of the stratosphere, air that has been transported through the extra-tropical tropopause will not penetrate into the stratosphere above $380 \mathrm{~K}$ and is mixed with the downwelling air from the overworld $(>380 \mathrm{~K})$. However, satellite water vapour measurements indicated that relatively young air - air that recently crossed the tropical tropopause - can be found up to heights of about $450 \mathrm{~K}$ (Rosenlof et al., 1997).

Nevertheless, in the LMS tropospheric influence can mainly be detected in the so-called mixing zone, a layer above the local tropopause with a thickness up to $20-30 \mathrm{~K}$ (Fischer et al., 2001; Hoor et al., 2002). The vertical extent of this mixing layer depends on the strength of the transport processes between the troposphere and stratosphere and varies with the seasonal change of dynamics (e.g., Hoor et al., 2004). STE exhibits a strong seasonality. Appenzeller and Holton (1996) determined the net mass flux across the extratropical tropopause and found a maximum in late spring and a minimum in early autumn. However, downwelling of stratospheric air across the $380 \mathrm{~K}$ isentrope is the domi- nant process in winter, troposphere-to-stratosphere transport (TST) gains importance in summer, when the downwelling from the stratosphere is only weak (Ray et al., 1999; Dethof et al., 2000) and PV gradients in the region of the subtropical jet change (Chen, 1995; Haynes and Shuckburgh, 2000).

One useful tool to analyse the motions of air and transport processes are long-lived trace gases. Since the lifetimes of these tracers are longer than the time scale of the transport processes they are involved in, the distribution of tracers in the atmosphere is mostly determined by dynamics (e.g., Plumb and Ko, 1992). For example, in order to estimate transport into the northern mid-latitude LMS, Ray et al. (1999) used a simple mass-balance calculation. They derived fractions of air coming from above $380 \mathrm{~K}$ and across the tropopause from balloon profiles. They estimated that $80 \%$ of the air in the LMS air had been transported from the stratosphere above $380 \mathrm{~K}$ in May, while in autumn the stratospheric fraction decreased to values below $50 \%$. Hoor et al. (2005) calculated a trace gas budget for the northern LMS between $35^{\circ}$ and $75^{\circ} \mathrm{N}$ from airborne $\mathrm{CO}$ measurements, concentrating on transport from the tropical and extra-tropical troposphere and the stratosphere. Above the roughly $25 \mathrm{~K}$ strong mixing layer with influence from the extra-tropical troposphere, they find a contribution from the tropical troposphere ranging between about $35 \%$ in winter and spring to about $55 \%$ in summer and autumn.

In the high-latitude winter, the formation of the polar vortex is an additional factor which has to be considered when examining transport into the LMS. Since the polar vortex region is isolated from the mid-latitude stratosphere by mixing barriers (Juckes and McIntyre, 1987), distinct tracer mixing ratios form during the winter, when subsidence of photochemically aged air masses and ozone depletion is taking place. For the stratosphere above $400 \mathrm{~K}$, model simulations and observations have shown that mixing of polar vortex air into the mid-latitude stratosphere contributes to mid-latitude ozone loss (Konopka et al., 2003; Manney et al., 2005; WMO, 2007; Grooß et al., 2008). This mixing usually happens in springtime when the vortex breaks up and high-latitude air masses are transported to lower latitudes. Günther et al. (2008) quantified transport across the lower stratospheric Arctic vortex edge using CLaMS (Chemical Lagrangian Model of the Stratosphere) simulations. They derived a fraction of 5\% vortex air masses in the mid-latitude stratosphere in the Arctic winter 2003 before the vortex break-up, resulting in an estimated maximum ozone dilution of $50 \%$ in the mid-latitudes. As the transport barrier at the polar edge hinders isentropic transport only down to $400 \mathrm{~K}$ (Manney et al., 1994), at lower potential temperature levels faster transport into the mid latitudes is possible (Chen, 1994). Thus, transport of polar vortex air into the LMS can crucially influence the chemical and radiative balance of this region. 
Therefore, in the context of this work, high resolution measurements of long-lived tracers were performed and used to study transport into the LMS region in the Arctic winter 2002/2003. In winter, transport into the LMS can be assumed to happen along the following three pathways: (i) transport from the troposphere, (ii) downward advection from the middle stratosphere through the $400 \mathrm{~K}$ surface and (iii) in the polar vortex region subsidence of air from the polar vortex. Fractions of air originating in each of these source regions are determined with a mass balance calculation by using a set of highly accurate tracer measurements covering the polar vortex region as well as the mid latitudes of the Northern Hemisphere.

\section{A mass balance equation system}

In the context of this work, air in the LMS is assumed to be a mixture of (see Fig. 1)

1. air descending from the polar vortex $(\theta>400 \mathrm{~K})$ : fraction $f_{\text {vortex }}$,

2. air descending from the extra-vortex/mid-latitude stratosphere $(\theta>400 \mathrm{~K})$ : fraction $f_{\text {strat }}$,

3. and air transported isentropically from the extra-tropical tropopause region or the tropical stratosphere $(\theta<400$ $\mathrm{K})$ : fraction $f_{\text {trop. }}$.

Although the LMS is most commonly defined as the region between the tropopause and the $380 \mathrm{~K}$ isentrope, the $400 \mathrm{~K}$ isentrope was used as the upper boundary to include the transport from the lowest part of the tropical stratosphere, which exhibits a similar chemical composition as the upper troposphere for most of the tracers considered here.

The mixing ratio $\chi(\theta)$ of a tracer at the potential temperature $\theta$ in the lowermost stratosphere can thus be expressed by the following linear equation:

$\chi(\theta)=f_{\text {trop }} \chi_{\text {trop }}+f_{\text {strat }} \chi_{\text {strat }}+f_{\text {vortex }} \chi_{\text {vortex }}$

The mass balance Eq. (1) can be set up for the mixing ratios $\chi_{i}$ of tracers $i=(1,2, \ldots, n)$. Given the boundary values - the average mixing ratios of a tracer $i$ at the tropopause $\chi_{\text {trop }, i}$, in the mid-latitude stratosphere at $400 \mathrm{~K}$ $\chi_{\text {strat }, i}$ and inside the vortex at $400 \mathrm{~K} \chi_{\text {vortex }, i}-$ and the measured values $\chi_{i}(\theta)$ at the potential temperature $\theta$, the fractions $f$ can be derived for every data point by solving the linear equation system. The determination of the boundary conditions will be discussed below. With the constraint $f_{\text {trop }}+f_{\text {strat }}+f_{\text {vortex }}=1$, the fractions can be derived from at least two observed tracers. Using more than 2 tracers yields an over-determined equation system. The solution of this equation system is achieved by solving the linear least squares problem using matrix decompositions algorithms (i.e. singular value decomposition (SVD) or so-called

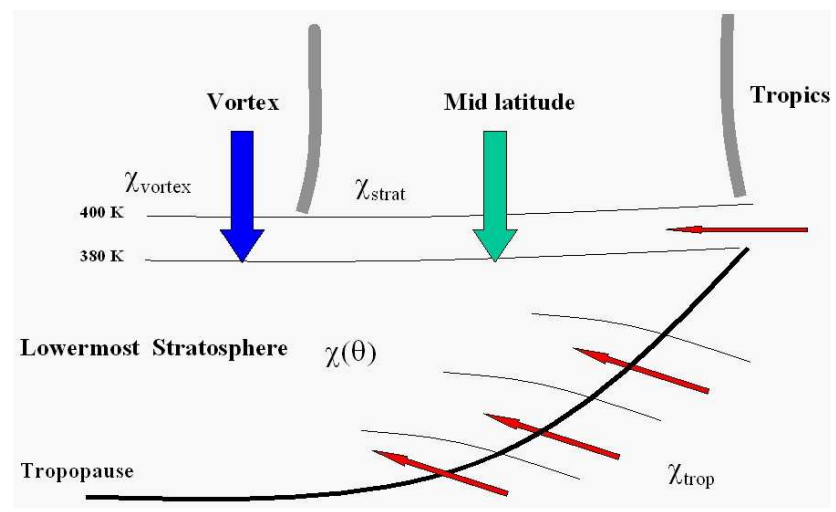

Fig. 1. Transport into the LMS. Air enters the LMS from the midlatitude stratosphere (green arrow), from the vortex region (blue arrow) and from the troposphere and the lowest part of the tropical stratosphere (red arrows).

QR/LQ decomposition, where the matrix of the linear equation system is decomposed into an orthogonal mxm and a triagonal nxm matrix) (Press et al., 1992; Bronstein et al., 1993).

The ideal set of tracers to solve this equation system is required to provide sufficiently complementary constraints on transport; e.g. the tracers should exhibit different source and sink regions, non-linear tracer-tracer relationships and thus provide sufficient mathematical independence of the involved equations. In order to yield representative boundary conditions, the ideal tracer is also spatially and temporally constant at the boundaries.

In reality, the requirements for the ideal tracer to solve the introduced mass balance equation system cannot be perfectly fulfilled. Horizontal and vertical gradients and imhomogenities are observed, especially in the vortex region, which can significantly influence the derived fraction results. However, only a limited number of tracers can be measured and amongst these, the best suited ones have to be used. In the context of this study $\mathrm{N}_{2} \mathrm{O}, \mathrm{CFC}-11\left(\mathrm{CCl}_{3} \mathrm{~F}\right), \mathrm{H}-1211$ $\left(\mathrm{CBrClF}_{2}\right), \mathrm{CH}_{4}, \mathrm{O}_{3}$ and $\mathrm{H}_{2} \mathrm{O}$ were selected. The method used to derive the boundary conditions of these tracers is described in Sect. 4.

\section{Data}

The presented tracer data (e.g. $\mathrm{CH}_{4}, \mathrm{O}_{3}$ and $\mathrm{H}_{2} \mathrm{O}$ plotted in Fig. 2) were obtained during the Vintersol - European Polar Stratospheric Cloud and Lee Wave Experiment (EuPLEx, 2004) and the ENVISAT - Arctic Validation Campaign (AVC). Based in Kiruna $\left(67^{\circ} 49^{\prime} \mathrm{N}, 20^{\circ} 30^{\prime} \mathrm{E}\right)$, altogether 15 flights were performed with the M55 Geophysica, a Russian high altitude research aircraft (Stefanutti et al., 1999), in the Arctic vortex region between $61^{\circ}$ and $80^{\circ} \mathrm{N}$ from January to March 2003. Additionally, data from the ENVISAT 

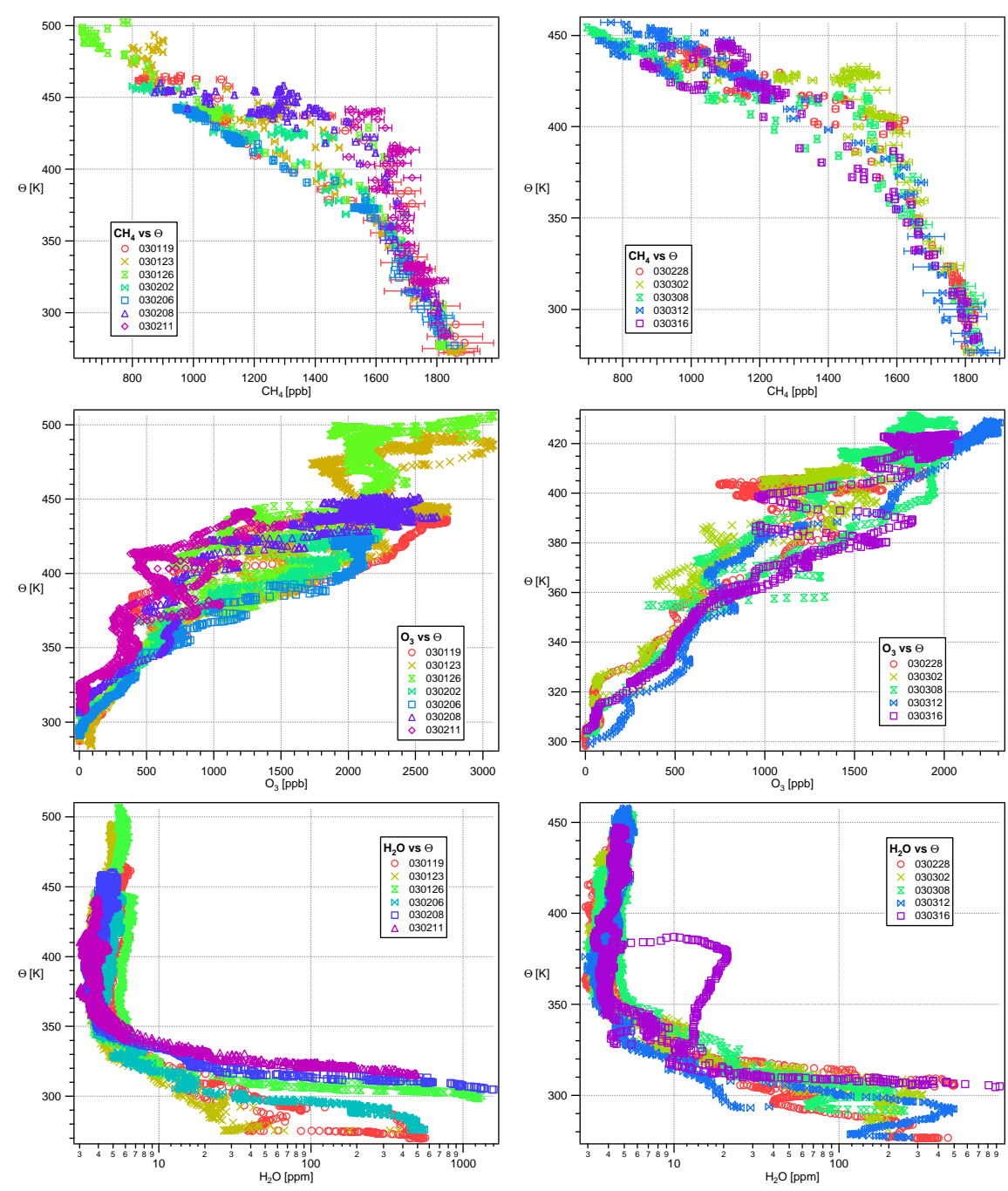

Fig. 2. Mixing ratios of $\mathrm{CH}_{4}$ (HAGAR), $\mathrm{O}_{3}$ (FOX) and $\mathrm{H}_{2} \mathrm{O}$ (FISH) plotted versus the potential temperature for all EuPLEx (left panel) and AVC flights (right panel). Error bars $\left(\mathrm{HAGAR} \mathrm{CH}_{4}\right)$ denote the precision of the measurement. For $\mathrm{O}_{3}$ the precision is $10 \%$, for $\mathrm{H}_{2} \mathrm{O}$ $0.3 \mathrm{ppm}$.

mid-latitude Test and Validation campaign in Forlí (Italy, October 2002) were used for comparison (Werner, 2006). An overview on the performed flights is given in Table 1 .

The measurements of the long-lived trace gases $\mathrm{N}_{2} \mathrm{O}$, CFC-11, H-1211 and $\mathrm{CH}_{4}$ were performed with the High Altitude Gas Analyser (HAGAR), a two-channel in-situ gas chromatograph with electron capture detectors (GC-ECD). The instrument was built at the Institute for Atmospheric and Environmental Sciences at the University of Frankfurt (Riediger, 2000; Strunk, 1999). The precision of the measurements is better than $1 \%$ for $\mathrm{N}_{2} \mathrm{O}, \mathrm{CFC}-11$ and $\mathrm{CH}_{4}$; $\mathrm{H}-1211$ is measured with a precision of $<3 \%$. Besides these trace gases, HAGAR measures CFC- $12\left(\mathrm{CCl}_{2} \mathrm{~F}_{2}\right), \mathrm{SF}_{6}$, $\mathrm{H}_{2}$ (GC-ECD) and $\mathrm{CO}_{2}$ (LiCOR, $\mathrm{CO}_{2}$-analyser (LI-COR, 1992)). The time resolution for the measurements is $90 \mathrm{~s}$. With a sample size of $2 \mathrm{ml}$ at a minimum sample flow of
$60 \mathrm{ml} / \mathrm{min}$, the sampling time is $2 \mathrm{~s}$ or faster. At a cruising speed of $750 \mathrm{~km} / \mathrm{h}(200 \mathrm{~m} / \mathrm{s})$ the horizontal resolution is about $400 \mathrm{~m}$. At average ascent and descent rates of the aircraft of $10 \mathrm{~m} / \mathrm{s}$ the vertical resolution is therefore $20 \mathrm{~m}$.

$\mathrm{H}_{2} \mathrm{O}$ was provided by the FISH Hygrometer of the Research Center Jülich. FISH measures total water by Lyman $\alpha$ photo-fragment fluorescence with a precision of $0.2 \mathrm{ppmv}$ and an absolute accuracy of $4 \%$ (Zöger et al., 1999). $\mathrm{O}_{3}$ measurements were performed by the FOX instrument (German Aerospace Center, DLR) using UV absorption (Schlager et al., 1997). The instrumental precision is around $10 \%$ for the FOX instrument.

Atmospheric pressure, temperature and flight parameters were provided by the UCSE (Unit for connection with Scientific Equipment) onboard the Geophysica (Sokolov and Lepouchov, 1998). 
Table 1. Data description of the tracer data plotted in Fig. 2, providing flight date, the range of equivalent latitude $\phi_{\text {equiv }}$ and the campaign name.

\begin{tabular}{lcl}
\hline flight date & $\phi_{\text {equiv }}\left[{ }^{\circ} \mathrm{N}\right]$ & description \\
\hline $01-19-2003$ & $48-70$ & EuPLEx \\
$01-23-2003$ & $65-85$ & EuPLEx \\
$01-26-2003$ & $59-73$ & EuPLEx \\
$02-06-2003$ & $64-80$ & EuPLEx \\
$02-08-2003$ & $42-48$ & EuPLEx \\
$02-11-2003$ & $36-51$ & EuPLEx \\
$02-28-2003$ & $53-71$ & AVC \\
$03-02-2003$ & $38-61$ & AVC \\
$03-08-2003$ & $61-82$ & AVC \\
$03-12-2003$ & $57-76$ & AVC \\
$03-16-2003$ & $52-77$ & AVC \\
\hline
\end{tabular}

For the work presented here, mean diabatic descent of trajectories within the vortex was derived from the trajectory module of the Chemical Lagrangian Model of the Stratosphere (CLaMS, McKenna et al., 2002) using ECMWF winds and cross-isentropic velocities calculated with the radiation scheme (see Fig. 2 in Konopka et al., 2004). The trajectories were started within the vortex from 1 December 2002 to 20 March 2003 in the $\theta$-region between 400 and $1400 \mathrm{~K}$. Furthermore, the tropopause height, defined here as the potential temperature of the 4.0 PVU surface was interpolated from the ECMWF data along the flight track.

\section{Determining boundary conditions}

In order to solve the equation system shown above, the distinct boundary values $\chi_{\text {trop }, i}, \chi_{\text {strat }, i}$ and $\chi_{\text {vortex }, i}$ for $i=\mathrm{N}_{2} \mathrm{O}$, CFC-11, $\mathrm{H}-1211, \mathrm{CH}_{4}, \mathrm{O}_{3}, \mathrm{H}_{2} \mathrm{O}$ had to be determined. The boundary conditions for $\mathrm{H}_{2} \mathrm{O}$ represent an exception and will therefore be discussed separately. The derived values for the boundary conditions and their errors are displayed in Table 2. The presented errors of each boundary condition are designed to describe the variability at the respective boundary due to vertical or horizontal gradients and inhomogenities of the respective tracer.

\subsection{The tropospheric boundary}

All used trace gases, except $\mathrm{O}_{3}$ and $\mathrm{H}_{2} \mathrm{O}$, are rather longlived compared to the transport times in the well- and fastmixed troposphere, and furthermore the tropopause is far away from the source and sink regions of these gases. Thus, spatial and temporal constancy can be assumed for the tropospheric boundary conditions, at least over the transport time scales of less than a few months that are considered in this study.
In order to determine the tropospheric boundary condition, we assume that all data with $\Delta \theta<-10 \mathrm{~K}$, i.e. $10 \mathrm{~K}$ below the local tropopause (defined here as the PV $=4 \mathrm{PVU}$ surface) belong to the troposphere. $\Delta \theta$ describes the distance in $\mathrm{K}$ potential temperature to the local tropopause.

Thus, the tropospheric boundary $\chi_{\text {trop }, i}$ for all tracers except $\mathrm{H}_{2} \mathrm{O}$ was calculated as the average mixing ratio from tracer measurements at least $10 \mathrm{~K}$ below $(\Delta \theta<-10)$ the local tropopause

$\chi_{\text {trop }, i}=\overline{\chi_{i}(\theta)}$ for $\Delta \theta<-10 \mathrm{~K}$ and $i \neq \mathrm{H}_{2} \mathrm{O}$.

The errors of the tropospheric boundary values were determined as the standard deviation of the corresponding tropospheric measurements as displayed in Table 2 .

The variability of the tropospheric boundary condition of $\mathrm{O}_{3}$, though being much larger than for the other gases, is however, negligible compared to the large differences between the tropospheric and stratospheric mixing ratios. In the case of $\mathrm{CH}_{4}$ distinct seasonal cycle and the latitudinal gradient of roughly $100 \mathrm{ppb}$ (ESRL, 2009) has to be regarded. However, HAGAR $\mathrm{CH}_{4}$ measurements from the mid latitudes (October 2002) and high latitudes (January to March 2003) match within $2 \%$ (not shown here). Thus, in the frame of this study the tropospheric $\mathrm{CH}_{4}$ mixing ratio from October to early spring is fairly described by an average value (including autumn and winter data) within an error range of $2 \%$.

\subsection{The extra-vortex stratospheric boundary}

Since the timescales of transport and mixing in the stratosphere are rather slow compared to the tropospheric ones, tracer measurements at the stratospheric boundary at $400 \mathrm{~K}$ at mid latitudes exhibit a relatively large variability (see Fig. 3). However, a comparison of extra-vortex tracer measurements at the $400 \mathrm{~K}$ isentrope at mid and high latitudes in autumn and winter (Forlí, 2002; EuPLEx, 2003; and Polaris, 1999; Newman et al., 1999) exhibits negligible differences between the seasons (not shown here) for e.g. $\mathrm{N}_{2} \mathrm{O}(4 \%), \mathrm{CFC}-11$ $(9 \%)$ and $\mathrm{CH}_{4}(3 \%)$. For the more sensitive tracers like $\mathrm{O}_{3}$ $(35 \%)$ or $\mathrm{H}-1211(12 \%)$ this change is more severe. Nevertheless, the observed inner-seasonal variability is of the same magnitude, thus the extra-vortex stratospheric boundary throughout the autumn-winter interval was assumed to be nearly constant with a adequate error describing this atmospheric variability (see below).

To calculate the stratospheric boundary values, the data had to be separated into vortex and non-vortex data. This was done with the help of a parameter $\Delta \chi_{\mathrm{N}_{2} \mathrm{O}}$ (Greenblatt et al., 2002; Ivanova et al., 2008), defined as the distance in ppb $\mathrm{N}_{2} \mathrm{O}$ to a reference vertical profile of $\mathrm{N}_{2} \mathrm{O}$ measured in the vortex region (see Fig. 7). A more detailed description is given in Appendix A.

The extra-vortex stratospheric boundary $\chi_{\text {strat, } i}$ was calculated as the average mixing ratio of tracer measurements between $395 \mathrm{~K}$ and $405 \mathrm{~K}$ performed during the mid-latitude 
Table 2. Boundary conditions $\chi_{\text {trop }}, \chi_{\text {strat }}$ and $\chi_{\text {vortex }}$ of the mass balance tracers $\mathrm{N}_{2} \mathrm{O}, \mathrm{CH}_{4}$, Halon-1211, CFC-11, Ozone and $\mathrm{H}_{2} \mathrm{O}$. $\delta \chi$ denotes the estimated error of the given boundary values.

\begin{tabular}{lllllll}
\hline Molecule & $\chi_{\text {trop }}$ & $\delta \chi_{\text {trop }}$ & $\chi_{\text {strat }}$ & $\delta \chi_{\text {strat }}$ & $\chi_{\text {vortex }}$ & $\delta \chi_{\text {vortex }}$ \\
\hline $\mathrm{N}_{2} \mathrm{O}$ & $315.84 \mathrm{ppb}$ & $2.16 \mathrm{ppb}$ & $299.17 \mathrm{ppb}$ & $18.35 \mathrm{ppb}$ & $\chi_{\text {vortex }, \mathrm{N}_{2} \mathrm{O}}(t)$ & $32 \mathrm{ppb}$ \\
$\mathrm{CH}_{4}$ & $1769.01 \mathrm{ppb}$ & $26.45 \mathrm{ppb}$ & $1655.52 \mathrm{ppb}$ & $105 \mathrm{ppb}$ & $\chi_{\text {vortex }, \mathrm{CH}_{4}}(t)$ & $131 \mathrm{ppb}$ \\
$\mathrm{Halon}-1211$ & $4.18 \mathrm{ppt}$ & $0.16 \mathrm{ppt}$ & $3.45 \mathrm{ppt}$ & $0.78 \mathrm{ppt}$ & $\chi_{\text {vortex }, \mathrm{H}_{12} 11}(t)$ & $0.64 \mathrm{ppt}$ \\
$\mathrm{CFC}-11$ & $258.3 \mathrm{ppt}$ & $2.48 \mathrm{ppt}$ & $230.34 \mathrm{ppt}$ & $32.75 \mathrm{ppt}$ & $\chi_{\text {vortex }, \mathrm{CFC}-11}(t)$ & $45 \mathrm{ppt}$ \\
Ozone & $48.69 \mathrm{ppb}$ & $8.3 \mathrm{ppb}$ & $522.65 \mathrm{ppb}$ & $347.3 \mathrm{ppb}$ & $\chi_{\text {vortex }, \mathrm{O}_{3}}(t)$ & $452 \mathrm{ppb}$ \\
$\mathrm{H}_{2} \mathrm{O}$ & $\mathrm{H}_{2} \mathrm{O}_{\text {entry }}(\theta)$ & $\delta \mathrm{H}_{2} \mathrm{O}_{\text {entry }}(\theta)$ & $3.8 \mathrm{ppm}$ & $0.5 \mathrm{ppm}$ & $4.4 \mathrm{ppm}$ & $0.32 \mathrm{ppm}$ \\
\hline
\end{tabular}

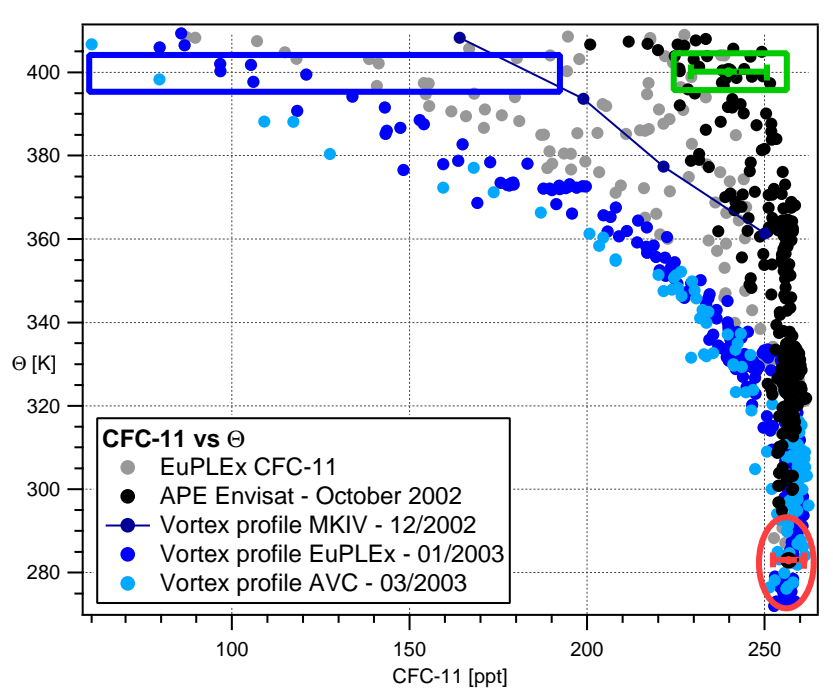

Fig. 3. Vertical profiles of HAGAR CFC-11 (ppt) plotted vs the potential temperature $\theta(\mathrm{K})$. Blue symbols indicate an early winter (dark blue line with dots), a mid winter (EuPLEx, dark blue circles) and a late winter (AVC, light blue circles) profile measured in the vortex region. A mid-latitude profile (October 2002) is displayed as black circles. Gray circles show all other data obtained in winter 2003. The data determining the boundary conditions are highlighted by frames.

campaign in October 2002 and the EuPLEx campaign with a $\Delta \chi_{\mathrm{N}_{2} \mathrm{O}}>60 \mathrm{ppb}$.

$$
\begin{aligned}
\chi_{\text {strat }, i}=\overline{\chi_{i}(\theta)}, & \text { for } 395 \mathrm{~K}<\theta<405 \mathrm{~K} \\
& \text { and } \Delta \chi_{\mathrm{N}_{2} \mathrm{O}}>60 \mathrm{ppb}
\end{aligned}
$$

The standard deviation of the data underestimates the atmospheric variability. The error is therefore more conservatively described by the half of the total span $\frac{|\max -\min |}{2}$ of those data points used for the calculation of the mean at $400 \mathrm{~K}$. The resulting uncertainties are specified in Table 2.

\subsection{The vortex boundary}

In the case of the vortex boundary, tracer mixing ratios are highly variable in time due to the fast subsidence in the vortex region. As seen in Fig. 3, the vortex profile is changing with time. During winter the profiles steepen and by the end of winter the strongest gradients are reached. The fast depletion of $\mathrm{O}_{3}$, occurring in the polar vortex above $400 \mathrm{~K}$, has to be considered as well. Concerning the usability of $\mathrm{O}_{3}$ as a tracer in the wintertime high-latitude LMS, it is argued here, that once $\mathrm{O}_{3}$ has descended to the LMS, it can be assumed to be rather conserved and further changes in mixing ratios or in the correlation with other tracers are produced predominantly by transport rather than chemistry. This assumption is supported by the observation that the compact, nearly linear correlation of $\mathrm{O}_{3}$ and $\mathrm{N}_{2} \mathrm{O}$ in the LMS is conserved throughout the winter (Hegglin et al., 2006), implying that $\mathrm{O}_{3}$ is not effected by local chemistry, otherwise the correlation with a long-lived tracer like $\mathrm{N}_{2} \mathrm{O}$ would not stay linear.

In order to take into account the time dependence, a variable boundary condition is derived that provides distinct values dependent on the time at which the descending vortex air has passed the $400 \mathrm{~K}$ surface, as explained in the following. First, $\chi_{\text {vortex }, i}$ is derived as a function of time from several profiles observed throughout the winter. For every vortex profile as depicted for CFC-11 in Fig. 3, $\chi_{\text {vortex }}$ was determined as the average mixing ratio

$$
\begin{aligned}
\chi_{\text {vortex }, i}=\overline{\chi_{i}(\theta)}, & \text { for } 395 \mathrm{~K}<\theta<405 \mathrm{~K} \\
& \text { and } \Delta \chi_{\mathrm{N}_{2} \mathrm{O}}<5 \text { ppb and } i \neq \mathrm{H}_{2} \mathrm{O}
\end{aligned}
$$

where the chosen $\Delta \chi_{\mathrm{N}_{2} \mathrm{O}}$ range ensures that only data are used that were measured inside the polar vortex. With several profiles of a tracer inside the vortex during the evolution of the winter, it is thus possible to determine an average mixing ratio at $400 \mathrm{~K}$ as a function of time, $\chi_{\text {vortex }, i}(t)$. In addition to the EuPLEx and AVC measurements, data from the Fourier Transform Infrared Interferometer MKIV instrument from a balloon flight on 16 December 2002 (launched at Esrange, Sweden, $67^{\circ} 53^{\prime} \mathrm{N}, 21^{\circ} 04^{\prime} \mathrm{E}$ ) were available. The MKIV flight was the earliest observation made inside the vortex during that winter and the corresponding tracer profiles describe the initial condition for the early vortex.

In Fig. $4, \chi_{\text {vortex }}(t)$ is plotted for all tracers used here. In order to synchronize this calculation with the CLaMS simulations, all changes refer to 1 December 2002 (see below), when the vortex was already fully developed. The MKIV profiles were used as the corresponding initial tracer profiles 


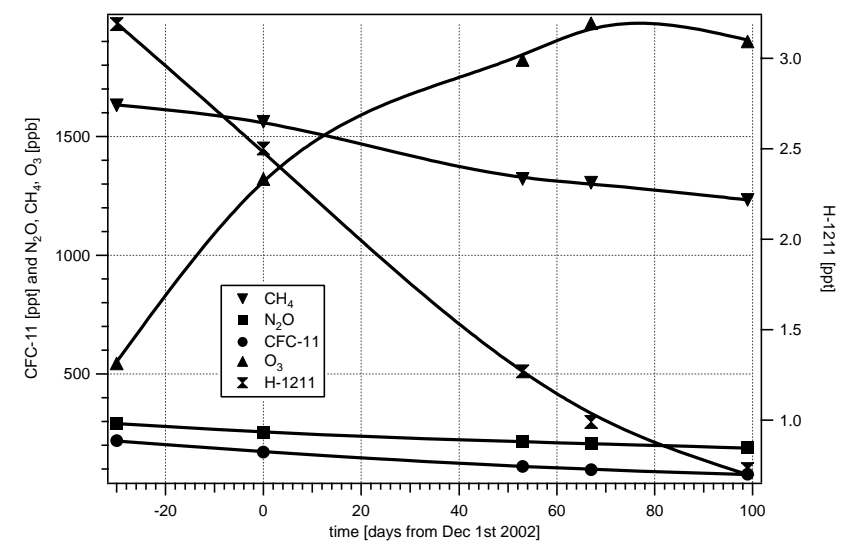

Fig. 4. Averages of tracers at the $400 \mathrm{~K}$ isentrope in the vortex versus the time $\left(\chi_{\text {vortex }}(t)\right)$. The data were fitted with a smoothing spline. Points refer to measurements made during Geophysica campaigns and the MKIV flight.

on 1 December 2002. The information on $\chi_{\text {vortex }}(t)$ before this date does not explicitly enter the calculation of the vortex boundary values but is important for the form of the fitting function (smoothing spline). Thus, to complete the set and describe the pre-vortex status in the high-latitude fall, the stratospheric boundary condition was used and regarded as the initial condition at the $400 \mathrm{~K}$ isentrope in high latitudes at the end of autumn before the development of the vortex. It was dated to the 1 November 2002, which is an approximate date for the beginning of the descent and the development of the vortex (R. Müller, personal communication, 2004).

In order to calculate a corresponding vortex boundary value for every data point in the LMS, the time when the air parcels crossed the $400 \mathrm{~K}$ isentrope and thus entered the LMS had to be determined. The necessary information about the descent rates below the vortex were provided by CLaMS calculations initialized on 1 December 2002. The trajectories of the descent are displayed in Fig. 5. Starting from the time and the potential temperature of the measurement, the CLaMS descent rates were used to calculate the time $t_{400 \mathrm{~K}}$ when an air parcel crossed the $400 \mathrm{~K}$ isentrope. With the knowledge of $\chi_{\text {vortex, } i}(t)$ it is then possible to determine the corresponding mixing ratio $\chi_{\text {vortex }, i}$ at the time $t_{400 \mathrm{~K}}$ for every data point inside the LMS. In case the air parcel is already found below $400 \mathrm{~K}$ on December 1, the corresponding vortex boundary value is set to the mixing ratio at $400 \mathrm{~K}$ on 1 December 2002. Since there were no high-precision measurements in the high-latitude LMS region available prior to 1 December, assumptions on the descent and the evolution of the mixing ratios at $400 \mathrm{~K}$ in the early, developing vortex would not yield a more accurate estimate.

The total error of the vortex boundary value $\delta \chi_{\text {vortex }, i}$ as displayed in Table 2 is estimated as $\delta \chi_{\text {vortex }, i}=$ $\sqrt{\delta \chi_{\mathrm{descent}, i}^{2}+\delta \chi_{\mathrm{atm}, i}^{2}} . \quad \delta \chi_{\mathrm{descent}, i}$ is the estimated error of

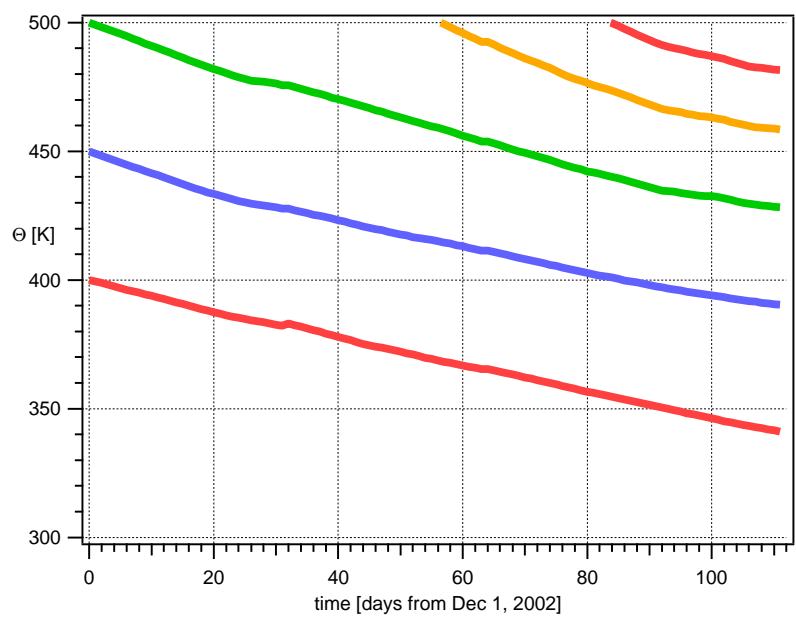

Fig. 5. Mean diabatic descent (solid lines) within the vortex derived from an ensemble of CLaMS trajectories starting on 1 December 2002.

the descent trajectories of the CLaMS model and $\delta \chi_{\mathrm{atm}, i}$ describes the atmospheric variability of the tracer $i$ in the vortex region at $400 \mathrm{~K}$.

The atmospheric variability $\delta \chi_{\mathrm{atm}, i}$ is calculated as the standard deviation of the data used to calculate the mean mixing ratio of a tracer $i$ at $400 \mathrm{~K}$ (see Eq. 4). The error in the CLaMS descent calculation can be assumed to be about $20 \%$ in the lower stratosphere (conservative estimate). With air parcels descending from the $400 \mathrm{~K}$ isentrope by about $60 \mathrm{~K}$ during the winter from 1 December 2002 to 20 March 2003, this would lead to an absolute error in the determination of the potential temperature of $12 \mathrm{~K}$. An error of $12 \mathrm{~K}$ in the determination of the average mixing ratio at $400 \mathrm{~K}$ translates into an error in mixing ratio at $400 \mathrm{~K}$ dependent on the local vertical gradient of a tracer $i$.

As the measurements are performed, in the worst case, with a precision of $3 \%(\mathrm{H}-1211)$, the measurement error can be neglected compared to $\delta \chi_{\text {descent }, i}$ and $\delta \chi_{\text {atm }, i}$. The dominant factor is the error in the determination of the descent inside the vortex.

The error in the constructed time evolution of $\chi_{\text {vortex }, i}$ (Fig. 4) is hard to assess. Due to the sparsity of the available tracer measurements, the form of the fit function is arbitrary. However, given the smooth forms of the simulated descent trajectories (Fig. 5) and of the observed profiles (Fig. 3), it is clear that a smooth interpolation between the various measurements (Fig. 4) will be a reasonable estimate for $\chi_{\text {vortex }, i}(t)$. Furthermore note, that an error in $\chi_{\text {vortex }, i}(t)$ will have a similar effect as an error in $t_{400}$, which is accounted for in $\delta \chi_{\text {descent }, i}$. Considering that $\delta \chi_{\text {descent, } i \text { was es- }}$ timated quite conservatively, the error in $\chi_{\text {vortex }, i}(t)$ will not be considered explicitly here. 


\subsection{Boundary conditions for $\mathrm{H}_{2} \mathrm{O}$}

The tropospheric boundary value of $\mathrm{H}_{2} \mathrm{O}$ has to be considered separately from the other tracers. The quantity of $\mathrm{H}_{2} \mathrm{O}$ that enters the stratosphere by crossing the tropopause depends on the temperature at the tropopause. Thus, the entry mixing ratio of $\mathrm{H}_{2} \mathrm{O}$ is not a constant but a function of time and potential temperature. The values used in this work were derived from a fit to a climatology of $\mathrm{H}_{2} \mathrm{O}$ entry values by Krebsbach (2005) based on measurements performed in the UT/LS region during the SPURT (Engel et al., 2006) and POLSTAR (Polar Stratospheric Aerosol Experiment; 1997/98) campaigns. The $\mathrm{H}_{2} \mathrm{O}$ entry values were derived by determining the end members of mixing lines in the $\mathrm{H}_{2} \mathrm{O} / \mathrm{O}_{3}$ correlation, in a similar way as done in Hoor et al. (2002) for $\mathrm{CO} / \mathrm{O}_{3}$ correlations.

Only autumn and winter data were used (OctoberFebruary). The derived entry function $\mathrm{H}_{2} \mathrm{O}_{\text {entry }}(\theta)$ for the LMS is displayed in Fig. 6 (black line) together with $\mathrm{H}_{2} \mathrm{O}$ measurements obtained during the EuPLEx and AVC campaigns, provided by the FISH instrument.

With this entry function, a $\mathrm{H}_{2} \mathrm{O}$ entry value can be determined for every potential temperature between $300 \mathrm{~K}$ and $380 \mathrm{~K}$. Above $380 \mathrm{~K}$, the entry value of $\mathrm{H}_{2} \mathrm{O}$ is set constant at $3.5 \mathrm{ppm}$, since transport through the cold tropical tropopause certainly leads to the lowest entry values. Engel et al. (1996) derived a globally averaged entry value for $\mathrm{H}_{2} \mathrm{O}$ from $\mathrm{H}_{2} \mathrm{O} / \mathrm{CH}_{4}$ correlations and calculated a value of $3.61 \pm 0.28$ ppmv.

The error of the $\mathrm{H}_{2} \mathrm{O}$ boundary value was estimated separately for three potential temperature regions as the standard deviation of the residuals from the derived entry function $\mathrm{H}_{2} \mathrm{O}_{\text {entry }}(\theta)$ within each region:

$$
\begin{aligned}
& \theta<340 \mathrm{~K}: 10 \mathrm{ppm}, \\
& 340 \mathrm{~K}<\theta<360 \mathrm{~K}: 6 \mathrm{ppm}, \\
& \theta>360 \mathrm{~K}: 1 \mathrm{ppm} .
\end{aligned}
$$

The derived tropospheric boundary value assumes an isentropic transport into the stratosphere. However, the above given error margins can be translated into a vertical potential temperature interval and thus account for a probable cross isentropic transport (e.g. an error of $10 \mathrm{ppm}$ in $\mathrm{H}_{2} \mathrm{O}$ at theta levels below $340 \mathrm{~K}$ accounts for a cross-isentropic transport of roughly $\pm 20 \mathrm{~K}$; see Fig. 6).

The extra-vortex stratospheric and vortex boundary values for $\mathrm{H}_{2} \mathrm{O}$ are determined more easily as $\mathrm{H}_{2} \mathrm{O}$ is almost constant at values of 3-6 ppm above $400 \mathrm{~K}$. The FISH data were split up into vortex data with a $\Delta \chi_{\mathrm{N}_{2} \mathrm{O}}$ between -25 and $5 \mathrm{ppb}$ and non-vortex data with a $\Delta \chi_{\mathrm{N}_{2} \mathrm{O}}$ larger than $60 \mathrm{ppb}$. The resulting value for the stratosphere at $400 \mathrm{~K}$ outside the vortex is $3.8 \mathrm{ppm} \pm 0.5 \mathrm{ppm}$ and the value for the vortex at $400 \mathrm{~K}$ is $4.4 \mathrm{ppm} \pm 0.32 \mathrm{ppm}$. Both values were calculated as the averages between $395 \mathrm{~K}$ and $405 \mathrm{~K}$. The errors of the

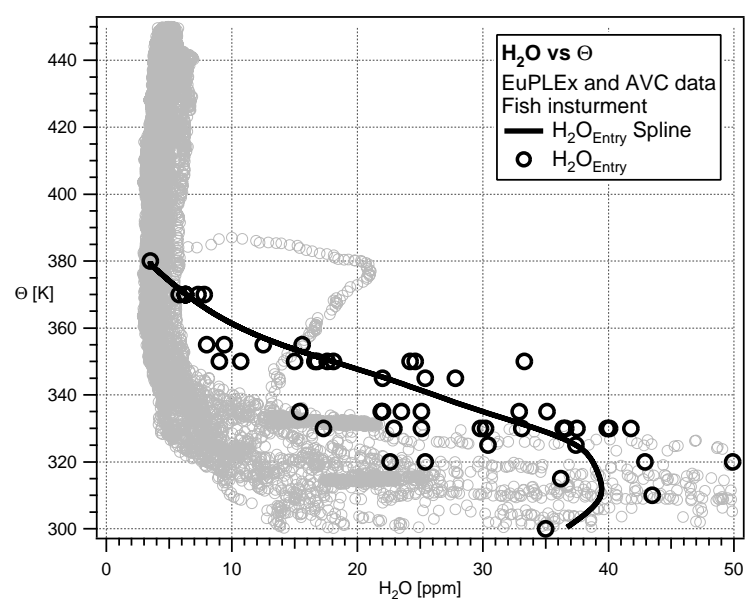

Fig. 6. $\mathrm{H}_{2} \mathrm{O}$ data plotted versus the potential temperature. Small grey circles show FISH data during the EuPLEx/AVC campaigns, large black circles mark the $\mathrm{H}_{2} \mathrm{O}$ entry values given by Krebsbach (2005) and the black line denotes the $\mathrm{H}_{2} \mathrm{O}$ entry fit, $\mathrm{H}_{2} \mathrm{O}_{\text {entry }}(\theta)$, used to derive tropospheric boundary values.

boundary values are derived from the standard deviation of the corresponding measurements.

\section{Results}

\subsection{Classification of data}

In the vortex edge region, the mixing ratios vary depending on how strongly the air parcels are influenced by the vortex (see Fig. 2). Air strongly influenced by the vortex generally exhibits high $\mathrm{O}_{3}$ mixing ratios and low mixing ratios of the other species compared to air weakly influenced by the vortex. In order to get a better overview on the results, only the results of two extreme sub-sets of the data are considered separately in this mass balance study:

i. heavily vortex-influenced data below the vortex and,

ii. LMS data with little vortex influence.

The division of the data into these sub-sets is achieved by establishing an upper envelope and a lower envelope profile of the vertical $\mathrm{N}_{2} \mathrm{O}$ distribution. In Fig. 7, the data of the lower envelope profile (hereafter called "low $\mathrm{N}_{2} \mathrm{O}$ data") are enclosed by black squares. Data belonging to the upper envelope profile (hereafter called "high $\mathrm{N}_{2} \mathrm{O}$ data") are enclosed by black circles. Both profiles were derived by using the parameters $\Delta \chi_{\mathrm{N}_{2} \mathrm{O}}$ and $\Delta \chi_{\mathrm{N}_{2} \mathrm{O}_{\text {extra }}}$ which are described in Appendix A. This separation by $\mathrm{N}_{2} \mathrm{O}$ was performed for all tracers of both the EuPLEx and AVC data sets. This separation procedure is useful as the mixing ratio of a long-lived tracer provides a classification by chemical composition and thus transport history over much longer timescales than potential temperature or equivalent latitude (Ivanova et al., 2008). 

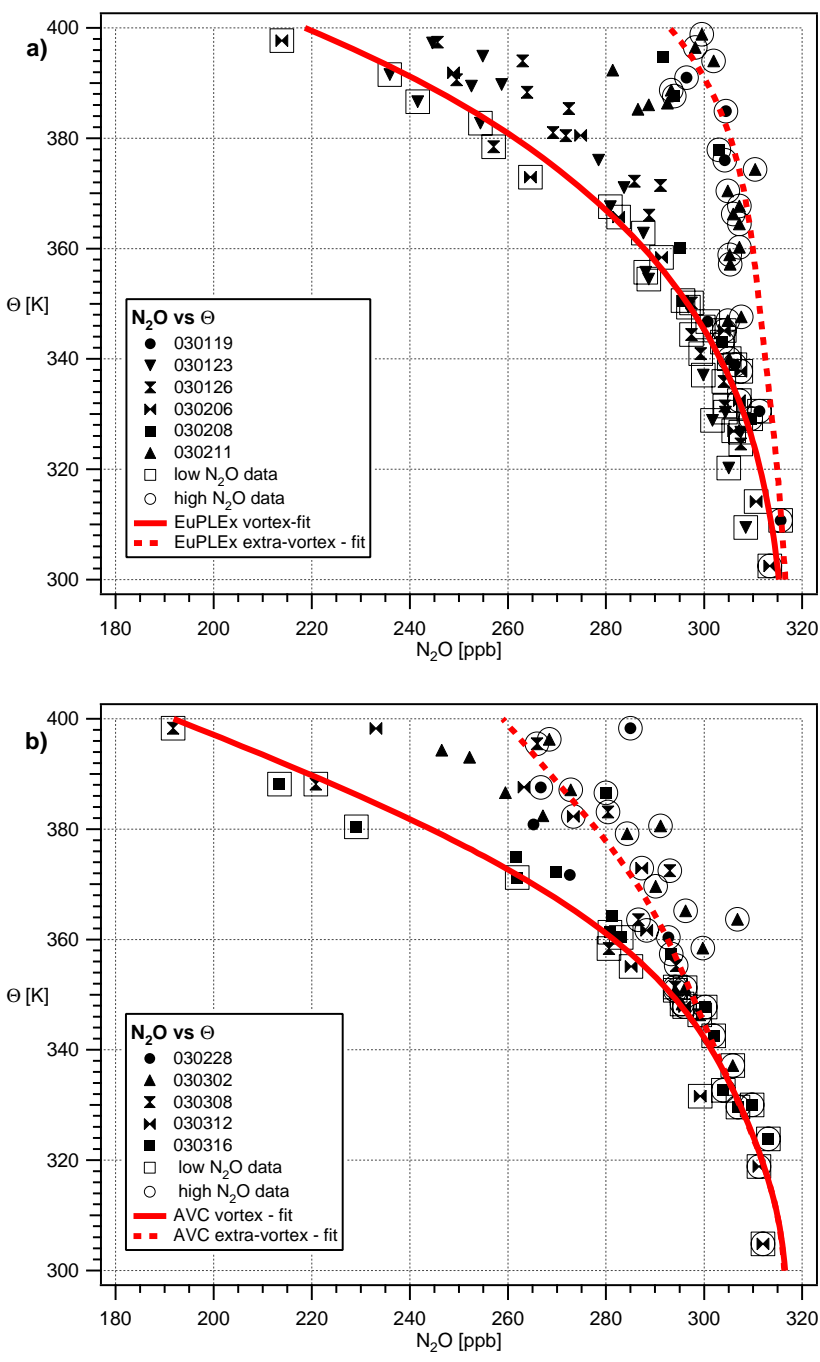

Fig. 7. $\mathrm{N}_{2} \mathrm{O}(\mathrm{ppt})$ plotted versus the potential temperature $\theta(\mathrm{K})$ in the LMS for EuPLEx (a) and $\operatorname{AVC}$ (b). The "low $\mathrm{N}_{2} \mathrm{O}$ data" are highlighted by black squares and the "high $\mathrm{N}_{2} \mathrm{O}$ data" are highlighted by black circles. The corresponding Vortex (line) and ExtraVortex fit (dashed line) are plotted in red.

Next, in order to remove the influence of the size of absolute values of the different tracer mixing ratios on the numerical solution of the mass balance equation, the data were normalized. In addition the quality of the single tracer was taken into account by a weighting factor. The weighting and normalization procedures are explained in the appendix.

Figures 8 and 9 show the results of the mass balance calculation as described in Sect. 2. As described above, these results exhibit the extremes of the analysis and provide an overview on the most and least vortex-influenced data in the LMS. Fractions of all other data points fill the space between the "low $\mathrm{N}_{2} \mathrm{O}$ data" and the "high $\mathrm{N}_{2} \mathrm{O}$ data" profiles. The fractions of air originating from the troposphere (red) and the stratosphere above $400 \mathrm{~K}$ inside (blue) and outside (green) the vortex are plotted versus the potential temperature. For each fraction, the results of the individual data points are shown as well as an average profile as described in the following section. Displayed are only data that were obtained above the tropopause between $300 \mathrm{~K}$ and $400 \mathrm{~K}$. The error bars are also discussed in detail in the following section.

\subsection{Sensitivity of the calculation to errors in the boundary conditions}

As mentioned above, the here used tracers are not ideal and at the proposed boundaries inhomogenities and vertical and horizontal gradients are observed. However, this variability has been accounted for by assuming error margins for at the respective boundary values. In order to analyse the sensitivity of the solution of the linear equation system to the values of the boundary conditions, a Monte Carlo simulation was performed. The linear equation system was solved with simultaneously varying boundary values. Each boundary value was randomly varied according to a Gaussian probability distribution, centered on its nominal value with a standard deviation equal to its estimated uncertainty as given in Table 2. This calculation was performed $10^{5}$ times for every data point. The average values of the results for each single data point are shown in Figs. 8 and 9. The corresponding error bars are defined as the range from the 16th to the 84th percentile of the distribution of the results for $10^{5}$ calculations, where the lowest and highest $16 \%$ of the data are cut off corresponding to $\pm 1 \sigma$ for a Gaussian distribution.

Average vertical profiles were calculated in steps of $10 \mathrm{~K}$ from $305 \mathrm{~K}$ to $395 \mathrm{~K}$ potential temperature as follows. For each averaging interval, cumulative histograms were calculated for the results of all data points falling into the interval $X \pm 5 \mathrm{~K}$. The average of the cumulative histogram is then taken as the average result within the $\theta$-interval. Error bars represent $1 / \sqrt{n}(n=$ number of points in the averaging interval) of the difference between the average and the 16th (lower error bar), respectively the 84th percentile (upper error bar) of the cumulative histogram. This error was chosen as an approximation to the $1 \sigma$ error of the mean value, as used in Gaussian statistics. The factor $1 / \sqrt{n}$ accounts for the error cancellation between $\mathrm{n}$ independent data points with Gaussian error distribution. Since the errors in the boundary values largely occur due to atmospheric variability and instrumental precision, the errors of the results for the individual data points can be regarded as independent.

Error bars are generally large, indicating a wide spread of the results of the Monte Carlo simulation. Furthermore, the calculated fractions are not always within the expected physical range of zero to one. However, they always match the physically reasonable range within their error bars.

One of the reasons for the large uncertainties is that the used tracers are almost linearly correlated with each other in the LMS (except $\mathrm{H}_{2} \mathrm{O}$ ). Thus, they do not always provide sufficiently independent constraints for the solution of the linear equation system. Together with the rather large 

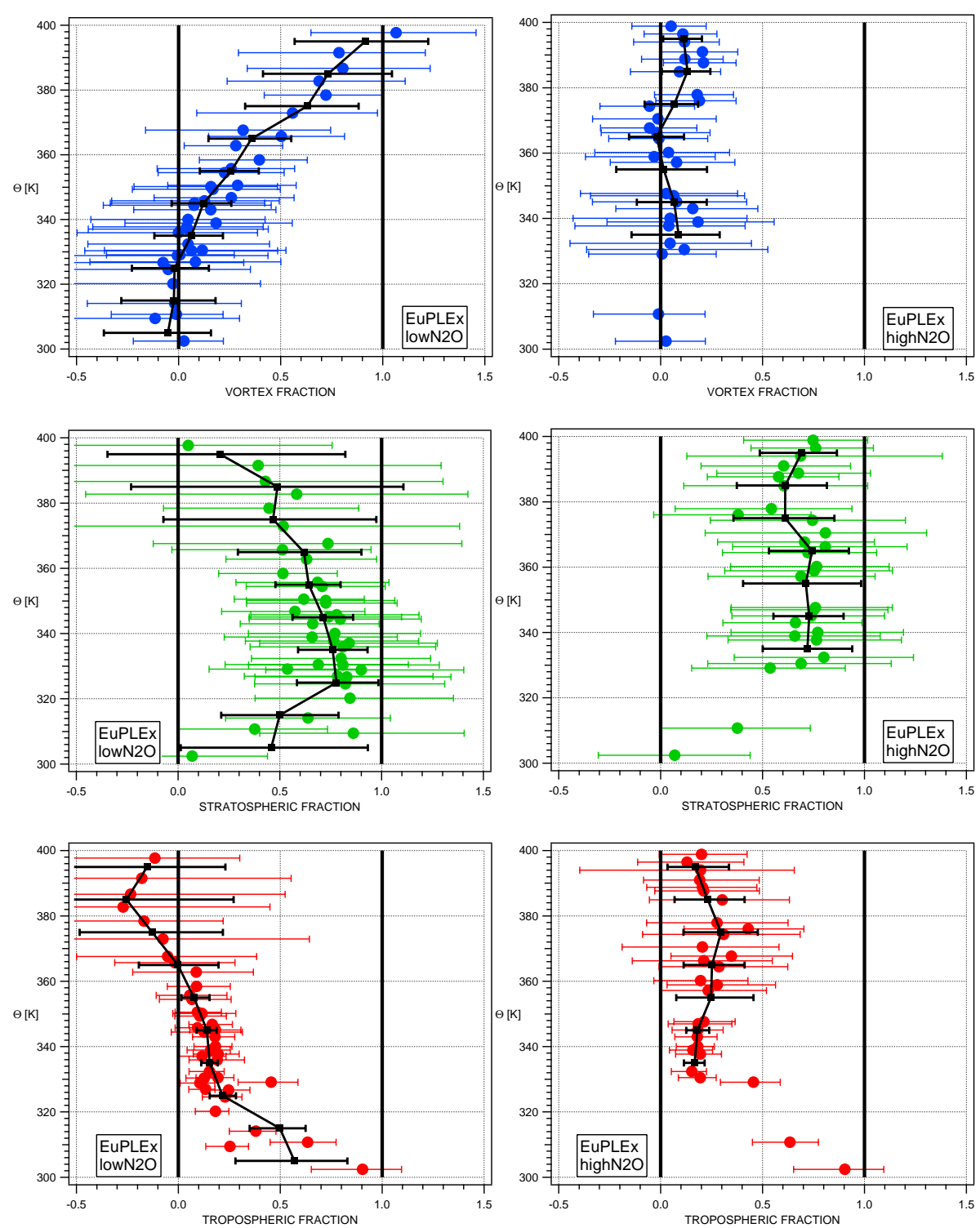

Fig. 8. Fractions of air in the LMS originating in the vortex (blue) region, the mid-latitude stratosphere (green) above $400 \mathrm{~K}$ and in the troposphere (red). Results for the "low $\mathrm{N}_{2} \mathrm{O}$ data" set (left panel) and "high $\mathrm{N}_{2} \mathrm{O}$ data" set (right panel) are shown for the EuPLEx campaign. Error bars range from the 16th to the 84th percentile for the individual data points. The profile averaged over $10 \mathrm{~K}$ bins is shown in black. Error bars of the average are divided by $\sqrt{n}$ where $n$ is the number of data points used for averaging in each bin.

uncertainties at the boundaries, the information fed into the linear equation system is thus providing imperfect constraints for the solution.

An additional problem can be created by the distribution of boundary values. While $\mathrm{H}_{2} \mathrm{O}$ yields good constraints for the definition of the tropospheric fraction, the vortex and the extra-vortex stratospheric boundary values are almost identical, thus not providing constraints on the respective fractions. With increasing $\theta$ even the constraint on the tropospheric fraction is gradually lost, since the variable boundary value for the tropospheric fraction approaches the other two boundary values at $400 \mathrm{~K}$, such that $\mathrm{H}_{2} \mathrm{O}$ hardly yields any constraints for the solution of the equation system at high $\theta$. As a result, the error bars are found to be relatively small for the tropospheric fraction below $360 \mathrm{~K}$ and become larger above. In parallel, the extra-vortex stratospheric and vortex fractions exhibit rather large error bars over the whole range of the LMS as a result of large uncertainties of the corresponding boundary conditions and the weak constraints from $\mathrm{H}_{2} \mathrm{O}$.

For all other tracers, the tropospheric and extra-vortex stratospheric boundary values are relatively close together (considering the large uncertainty of the latter), while the vortex boundary value is distinct from the other boundary 

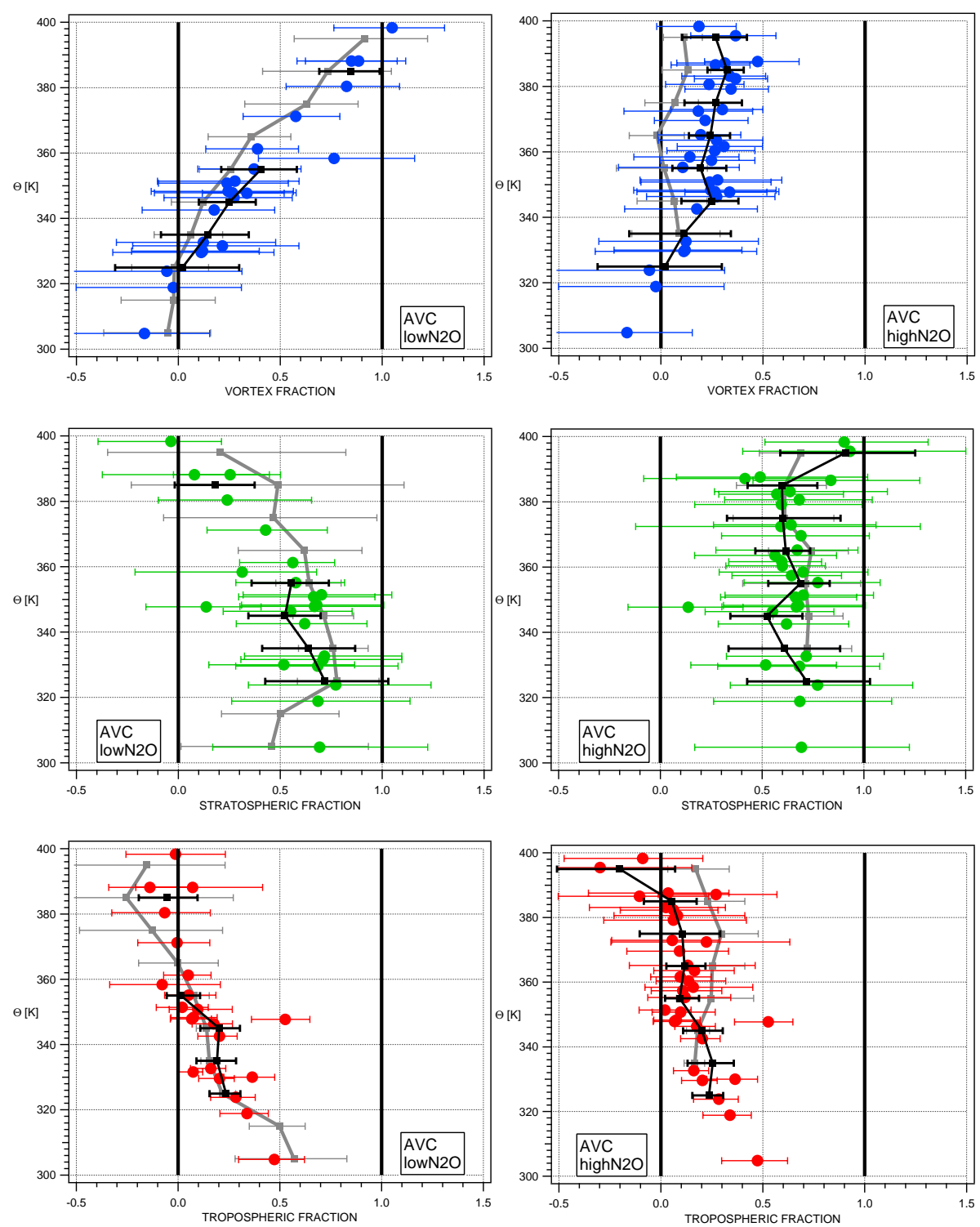

Fig. 9. Same as in Fig. 8, but for the AVC campaign. For intercomparison, the respective average profiles of the EuPLEx campaign have been added in grey.

values. Hence, in case of measured mixing ratios close to the vortex boundary value, the system still defines the vortex fraction relatively well, despite large uncertainties, while the determination of the other two fractions becomes difficult. Considering the variability at the extra-vortex stratospheric boundary, it is even possible that the difference between tropospheric and stratospheric boundary values is 0 . Despite the above shortcomings of the available tracer set to yield perfect constraints for the solution, the results and their error bars as displayed in Figs. 8 to 9 show that quantitative information can be obtained in most regions of interest.

\section{Discussion}

\subsection{Mid-winter data - January to early February 2003}

In the winter 2002/03 a relatively strong and cold Arctic vortex had developed in early December. This early vortex was stable and isolated until mid-January 2003 when a major stratospheric warming occurred. During a wave breaking event around the 21 January 2003 a splitting and re-merging of the vortex was observed (Günther et al., 2008). This process led to enhanced horizontal transport and strong filamentation of the lower stratospheric vortex. However, only little mixing is evident in the tracer data of the EuPLEx campaign above and below $400 \mathrm{~K}$. In Fig. 10a the potential temperature 

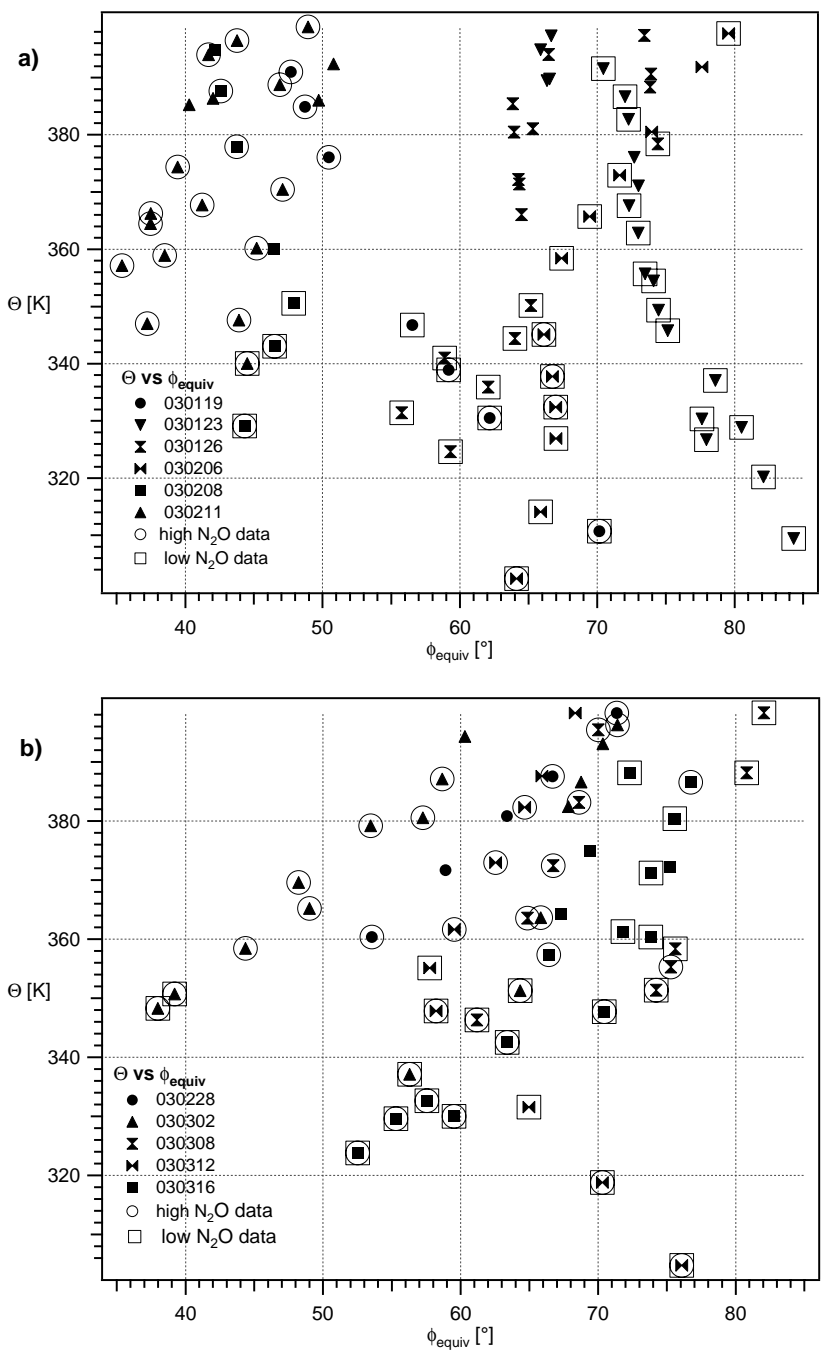

Fig. 10. Potential temperature plotted versus equivalent latitude. (a) Data of the EuPLEx Campaign, (b) data of the AVC campaign. The "low $\mathrm{N}_{2} \mathrm{O}$ data" are highlighted by black squares and the "high $\mathrm{N}_{2} \mathrm{O}$ data" are highlighted by black circles.

of the sampled air parcels between 300 and $400 \mathrm{~K}$ is plotted versus the equivalent latitude. Two distinct regions are evident, one at high equivalent latitude, which corresponds to the "low $\mathrm{N}_{2} \mathrm{O}$ data" (highlighted by squares) and one at low equivalent latitudes $40^{\circ}-50^{\circ} \mathrm{N}$ corresponding to the "high $\mathrm{N}_{2} \mathrm{O}$ data" (highlighted by circles).

\subsubsection{Heavily vortex-influenced data below the vortex}

The results for the heavily vortex influenced profiles from the EuPLEx campaign are shown in Fig. 8 (left panel). The results of the calculations show that these "low $\mathrm{N}_{2} \mathrm{O}$ data" are mostly dominated by air masses that have descended from the stratosphere. For these data, the extra-vortex stratospheric fraction ranges between $50 \%$ and $75 \%$ for $310 \mathrm{~K}<$ $\theta<370 \mathrm{~K}$; above $370 \mathrm{~K}$ it is not constrained by the observa- tions. No significant vortex influence is found in the lower half of the LMS, while the vortex fraction steadily increases in the upper half of the LMS. Around $370 \mathrm{~K}$, the LMS air is found to be a mixture of $\sim 50 \%$ vortex and $\sim 50 \%$ stratospheric air. Even higher, the vortex fraction increases to $100 \%$ at $400 \mathrm{~K}$. In parallel to the increasing influence of the vortex, the stratospheric influence must decrease, although, as mentioned above, this decrease cannot be quantitatively assessed due to the large error bars for $\theta>360 \mathrm{~K}$. The same is true for the tropospheric fraction above $360 \mathrm{~K}$, which is likely 0 . However, below $360 \mathrm{~K}$ the findings on the tropospheric influence are more reliable, as indicated by very small error bars. In the lowest $20 \mathrm{~K}$, tropospheric fractions are found to exceed $50 \%$; above that, they rapidly decrease to about $20 \%$ at $330 \mathrm{~K}$ (the tropopause was usually situated at $300 \mathrm{~K}$ ) and then gradually decrease further toward 0 at $360 \mathrm{~K}$. These results correspond well with findings of Hoor et al. (2004), who proposed a mixing layer above the tropopause in the LMS with increased tropospheric influence for the lowest $20-30 \mathrm{~K}$ above the tropopause.

\subsubsection{LMS data with little vortex influence}

The "high $\mathrm{N}_{2} \mathrm{O}$ data", which are taken at an equivalent latitude between $40^{\circ}$ and $50^{\circ} \mathrm{N}$, describe an air mass which is characteristic for the mid-latitude LMS region well equatorward of the vortex edge. Consequently, the mass balance calculation characterizes the region as mostly influenced by air masses which were transported from the extra-vortex stratosphere above $400 \mathrm{~K}$ (Fig. 8, right panel). Above the shallow layer with a pronounced tropospheric influence of $50-100 \%$ in the lowest $20 \mathrm{~K}$ of the LMS, the vortex and the tropospheric fractions remain small, while the extra-vortex stratospheric fraction varies between $50 \%$ and $70 \%$.

However, it can be observed that the tropospheric fraction is constantly calculated as significantly above 0 for all $\theta$ levels. Most of these measurements were obtained on 11 February 2003 (see Fig. 2) north of $68^{\circ}$ northern latitude. This result is in accord with a study by Curtius et al. (2005), who discuss unexpectedly high particle measurements in the LMS region that occurred during the flight on 8 February 2003. Although definite conclusions on the origin of these high particle concentrations could not be given, transport from the tropopause region was discussed as a possible cause and a trajectory analysis indeed showed evidence of transport from the lower latitude tropopause region into the high latitudes.

\subsection{Late winter - March 2003}

Compared to the strong wave forcing events in mid-winter with one major warming in late January as mentioned in the previous section and a second warming event in mid February, in early March only weak distortion of the vortex was observed (Günther et al., 2008). However, in the second week of March an increased wave forcing led to a distortion and 
elongation of the vortex towards the mid latitudes. The spatial separation between the "high-" and "low $\mathrm{N}_{2} \mathrm{O}$ data" is not as pronounced as observed in January and February during the EuPLEx campaign. In Fig. 10b it is evident that both data sets are distributed between $40^{\circ}$ and $80^{\circ} \mathrm{N}$. Equatorward $50^{\circ} \mathrm{N}$ only data from the flight on 2 March 2003 are found, which were obtained along the southern most flight path during the AVC campaign.

\subsection{Heavily vortex-influenced data below the vortex}

During the course of the winter, more and more air masses are transported into the LMS through the bottom of the vortex. Thus, in the upper region of the LMS an increased vortex fraction is evident (Fig. 9, upper left panel). The increase in vortex fraction already starts at $330 \mathrm{~K}$ and at $360 \mathrm{~K}$ the vortex influence is already around $50 \%$, while the extra-vortex stratospheric fraction decreases and becomes smaller than $50 \%$ for $\theta>360 \mathrm{~K}$. The tropospheric influence in the lowest $20 \mathrm{~K}$ of the LMS has decreased somewhat compared to early winter but is still evident with values between $30 \%$ and $50 \%$.

Although the vortex fraction is somewhat larger than in early winter, it should be pointed out that the March 2003 vortex had already experienced large scale mixing events with two major warmings. Thus the air in the vortex above $400 \mathrm{~K}$ cannot be regarded as purely original vortex air but has already experienced some dilution by mid-latitude air (Grooß et al., 2008; Günther et al., 2008). Note that the vortex fraction derived here is strictly the fraction of air descending through the vortex bottom at $400 \mathrm{~K}$, disregarding its previous history.

\subsection{LMS data with little vortex influence}

In the late winter "high $\mathrm{N}_{2} \mathrm{O}$ data" a tropospheric fraction significantly above 0 is only evident below $340 \mathrm{~K}$ with values from $50 \%$ at $300 \mathrm{~K}$ to values of $20 \%$ around $330 \mathrm{~K}$. The extra-vortex stratospheric fraction stays above $50 \%$ at all levels and increases to $100 \%$ at $400 \mathrm{~K}$.

As mentioned above the "high $\mathrm{N}_{2} \mathrm{O}$ data" of the AVC campaign are distributed from $40^{\circ} \mathrm{N}$ equivalent latitude (at about $340 \mathrm{~K})$ to $70^{\circ} \mathrm{N}$ equivalent latitude. Nevertheless, they yield a homogeneous result for the vortex fraction which is relatively well defined and stays constant at values of about $25 \%$ to $30 \%$ between $340 \mathrm{~K}$ and $390 \mathrm{~K}$ (Fig. 9, right panel). This implies some in-mixing of vortex air masses into the midlatitude LMS and furthermore a quite well mixed LMS.

At this point it should be noted, that the air at $400 \mathrm{~K}$ in March originated at $450 \mathrm{~K}$ in the beginning of December (see CLaMS trajectories in Fig. 5). Thus the impact of ozone depletion on these air masses is only very small as the major ozone depletion takes place in January/February above $450 \mathrm{~K}$ (Grooß et al., 2008).

\section{Conclusions}

In a simple mass balance study, fractions of air in the Arctic lowermost stratosphere originating from the tropopause, the extra-vortex stratosphere above $400 \mathrm{~K}$ and the vortex region above $400 \mathrm{~K}$ were calculated applying a linear equation system. This linear equation system was solved via least squares adjustment using the HAGAR $\mathrm{N}_{2} \mathrm{O}, \mathrm{CH}_{4}, \mathrm{CFC}-11, \mathrm{H}-1211$ as well as $\mathrm{O}_{3}$ (FOX, DLR) and $\mathrm{H}_{2} \mathrm{O}$ (FISH, FZ Jülich) measurements from the EuPLEx and the ENVISAT AVC campaigns in January-March 2003.

The results are based on a number of flights performed over Sweden and may thus not be representative for the whole Northern Hemisphere. However, given the data were sampled over an equivalent latitude range between $40^{\circ}$ and $80^{\circ} \mathrm{N}$, they provide good spatial and temporal coverage of the northern European mid- to high-latitude LMS in the winter 2003. Although the results exhibit large error bars in some regions, they generally allow to draw a quantitative picture about the origin of air mass in the Arctic LMS.

The EuPLEx and AVC results show a shallow layer of about $20 \mathrm{~K}$ above the tropopause with an increased tropospheric influence. During EuPLEx, the tropospheric fraction in this layer is larger than 50\% and during AVC larger than $30 \%$. This corresponds well with the findings of Hoor et al. (2004), who postulate a shallow mixing layer in the lowest $20-30 \mathrm{~K}$ of the LMS region where an enhanced tropospheric fraction of air can be found. Above this layer, the tropospheric influence is only minor with values lower than $20 \%$; above $350 \mathrm{~K}$, the tropospheric fraction is mostly not significantly different from zero. However, it should be kept in mind that this study only considers transport in the time between autumn and winter, thus, any tropospheric influence that already existed in autumn is neglected: Air masses at the stratospheric boundary at $400 \mathrm{~K}$ which are used to determine the stratospheric boundary condition, might of course be influenced by tropospheric air already. Thus, the absolute fraction of tropospheric air might be larger than there given tropospheric fractions. The latter refer to the time frame autumn/winter and to changes since then.

Such a recent transport event was probably observed during the EuPLEx campaign, where slightly increased tropospheric fractions (up to $30 \%$ ) are derived above $350 \mathrm{~K}$ for "high $\mathrm{N}_{2} \mathrm{O}$ data". This observation of transport from the tropical tropopause region is consistent with trajectory studies presented in Curtius et al. (2005). Furthermore, the data exhibiting this elevated tropospheric fraction were measured in the time after a first major warming which lead to a splitting and re-merging of the vortex linked with strong horizontal transport.

Above the tropospherically influenced region, the dominant fraction of air (average 75\%) descended from the midto high-latitude stratosphere outside the vortex. Only for the "low $\mathrm{N}_{2} \mathrm{O}$ data" data and at the highest levels the dominant fraction of air originates from the vortex region. One should, 
however, keep in mind that during the course of the winter the vortex above $400 \mathrm{~K}$ had already experienced some in-mixing of mid-latitude air masses such that the air descending through its bottom at $400 \mathrm{~K}$ in the vortex region is not pure original (i.e. early-winter) vortex air (Günther et al., 2008). In this study, the history of air above $400 \mathrm{~K}$ was not considered; rather all air entering the LMS through the vortex bottom at $400 \mathrm{~K}$ was defined as $100 \%$ vortex air. Thus, the vortex fraction derived here gives an upper limit for the fraction of original vortex air.

In January and early February a vortex fraction was derived for the "low $\mathrm{N}_{2} \mathrm{O}$ data" (equivalent latitude $>65^{\circ} \mathrm{N}$, see Fig. 10a) with values of $50 \%$ at $370 \mathrm{~K}$ increasing toward $100 \%$ at $400 \mathrm{~K}$. Further descent of air masses through the vortex bottom manifests itself in slightly larger vortex fractions for the AVC campaign than those derived for EuPLEx with about $50 \%$ vortex air at $360 \mathrm{~K}$ increasing to $100 \%$ at $400 \mathrm{~K}$ for equivalent latitudes $>70^{\circ} \mathrm{N}$. This increase of vortex fraction between EUPLEX and the AVC campaign is rather small, presumably because the main descent already happened before EuPLEx. The "high $\mathrm{N}_{2} \mathrm{O}$ data" also exhibit slightly higher vortex fractions for AVC than for EuPLEx with values constantly between $20 \%$ and $35 \%$ above $340 \mathrm{~K}$. As these data were gathered between $40^{\circ}$ and $70^{\circ} \mathrm{N}$ equivalent latitude, this indicates some mixing of vortex air between low and high latitudes in the course of the winter. Günther et al. (2008) derived for the same winter a pure vortex fraction of about $5 \%$ in extra-vortex air masses above $400 \mathrm{~K}$. Due to different definitions of boundary conditions and the vortex itself, the derived fractions from both studies are difficult to compare. However, as mixing above $400 \mathrm{~K}$ is expected to be inhibited by the local transport barrier of the polar vortex edge, a lower fraction of vortex air in the mid latitudes above $400 \mathrm{~K}$ is certainly expected.

As remarked in Sect. 6.4, the vortex air that descended and then mixed into the LMS had not experienced significant ozone depletion. Nevertheless, it represents air masses distinct from mid latitude air masses with respect to chemical and dynamical history. With a vortex fraction of about $30 \%$ observed at equivalent latitudes even as low as $40^{\circ} \mathrm{N}$, the composition of the mid- to high latitude northern European LMS in the early spring 2003 was significantly influenced by the vortex. The chemical composition of the Arctic vortex is known to vary strongly from year to year due to the variability of dynamic forcing. Furthermore, the Northern Hemisphere exhibits a significant longitudinal variability. Günther et al. (2008) and Grooß et al. (2008) showed that the winter 2002/2003 exhibited some extensive mixing across the vortex edge above $400 \mathrm{~K}$. Nevertheless, their derived numbers for the impact of vortex air to mid-latitude $\mathrm{O}_{3}$ depletion (40 to $50 \%$ ) in this winter are in agreement with earlier studies of other winters, implying that their derived numbers for the winter 2002/2003 are in a typical range.
Thus, if the vortex influence in the LMS as derived here is similarly strong for other winters and other regions, the interannually varying vortex composition can be expected to drive a significant interannual variability in LMS composition.

\section{Appendix A}

\section{Defining vortex and extra-vortex air masses}

For the separation of vortex from extra-vortex data, the equivalent latitude $\phi_{\text {equiv }}$ (McIntyre and Palmer, 1984) of the vortex edge at the potential temperature $\theta$ of a given measurement was determined by the Nash criterion (Nash et al., 1996) from potential vorticity (PV) (Ertel, 1942) data provided by the CLaMS model. HAGAR $\mathrm{N}_{2} \mathrm{O}$ data from the EuPLEx campaign were then filtered according to equivalent latitude relative to the vortex edge. All data measured $5^{\circ}$ equivalent latitude north of the vortex edge as defined by Nash (Nash et al., 1996) were considered as vortex data having not experienced any recent mixing with extra vortex air masses. Due to the definition of the vortex edge this criterion is only applicable down to $400 \mathrm{~K}$. However, the vortex edge above $400 \mathrm{~K}$ was generally situated north of $67^{\circ} \mathrm{N}$ equivalent latitude. Thus, below $400 \mathrm{~K}$ the vortex data were defined as data gathered at equivalent latitudes $\geq 67^{\circ} \mathrm{N}$. These data were obtained predominantly during the flight on 6 February 2003. The Geophysica flight path on that day was situated fully inside or below the vortex region. The fit through all the vortex or sub-vortex data, the "vortex ${ }_{\text {fit }}$ ", was then used to define a new parameter called $\Delta \chi_{\mathrm{N}_{2} \mathrm{O}}$ (Greenblatt et al., 2002; Ivanova et al., 2008), which defines the meridional distance given in $\mathrm{N}_{2} \mathrm{O}$ mixing ratio (ppb) from the $\mathrm{N}_{2} \mathrm{O}$ "vortex ${ }_{\mathrm{fit}}$ " at a given $\theta$.

$\Delta \chi_{\mathrm{N}_{2} \mathrm{O}}(\theta)=\chi_{\mathrm{N}_{2} \mathrm{O}}(\theta)-\chi_{\mathrm{N}_{2} \mathrm{O}_{\text {vortex fit }}}(\theta)$

Due to the subsidence in the vortex region, distinct vortex profiles had to be determined for each campaign. Thus, similar calculations were performed for the AVC data. The $\Delta \chi_{\mathrm{N}_{2} \mathrm{O}}$ for AVC refers to the AVC vortex profile.

The parameter $\Delta \chi_{\mathrm{N}_{2} \mathrm{O}}$ can be used to divide all tracer data throughout the stratosphere into vortex and non-vortex data. $\Delta \chi_{\mathrm{N}_{2} \mathrm{O}}$ has two advantages compared to using equivalent latitude to sort the data: (i) it is a quantity directly measured at high resolution rather than a processed low-resolution quantity; (ii) it is directly related to chemical air composition, whereas equivalent latitude is a purely dynamical diagnostic.

Similarly to $\Delta \chi_{\mathrm{N}_{2} \mathrm{O}}$ the parameter $\Delta \chi_{\mathrm{N}_{2} \mathrm{O}_{\text {extra }}}(\theta)$ defines the distance from the high latitude "high $\mathrm{N}_{2} \mathrm{O}$ data fit" $\mathrm{N}_{2} \mathrm{O}_{\text {extra fit }}(\theta)$.

$\Delta \chi_{\mathrm{N}_{2} \mathrm{O}_{\text {extra }}}(\theta)=\chi_{\mathrm{N}_{2} \mathrm{O}}(\theta)-\chi_{\mathrm{N}_{2} \mathrm{O}_{\text {extra fit }}}(\theta)$ 
The fit was calculated for data taken from flights or parts of flights that were performed outside the vortex region $\left(\phi_{\text {equiv }}<67^{\circ} \mathrm{N}\right)$, thus including only measurements with high $\mathrm{N}_{2} \mathrm{O}$ mixing ratios, implying little or even no vortex influence. For the EuPLEx campaign these were e.g. the flights on 8 and 11 February 2003. During the AVC campaign data were taken from the flights of the 2, 8 and 12 March 2003.

\section{Appendix B}

\section{Normalization of the tracer data}

The mixing ratios of the tracers used to solve the linear equation system span two orders of magnitude (ppt-ppm). In order to remove the influence of the size of absolute values of the different tracer mixing ratios on the numerical solution of the mass balance equation, the data were normalized relative to the span of mixing ratios which are considered in the LMS mass balance study following Eq. (B1):

$\chi_{\text {norm }}=\frac{\chi-\chi_{\text {vortex }}}{\chi_{\text {trop }}-\chi_{\text {vortex }}}$

with $\chi_{\text {norm }}=$ normalized tracer mixing ratio, $\chi=$ tracer mixing ratio, $\chi \widetilde{\text { vortex }}=$ average mixing ratio at the vortex boundary in the middle of the winter $2002 / 2003$, i.e. during EuPLEx, $\chi_{\text {trop }}=$ average mixing ratio at the tropopause.

This normalization results in values changing from about zero in the vicinity of the vortex boundary to about 1 at the tropopause. Now, every tracer enters the mass balance equation with the same weight, while the characteristic structure of each tracer in the LMS is preserved.

Since not every tracer provides information for the solution of the linear equation system with the same quality, a weighting of the single tracer equations is of advantage. As a measure for this quality, the normalized error at the worst defined boundary $\left(\chi_{\text {norm,max }}\right)$ was used. The mass balance equation of each tracer was thus multiplied with a weighting factor $W$ :

$$
W=\frac{1}{\delta \chi_{\text {norm, max }}^{2}}=\frac{1}{\left[\frac{\chi_{\max }}{\chi_{\text {trop }}-\chi_{\widetilde{\text { vortex }}}}\right]^{2}}
$$

Acknowledgements. The EUPLEX campaign was funded by the European Union and the ENVISAT Arctic Validation campaign was supported by the European Space Agency and the German BMBF. Furhtermore, the authors would like to thank the crew and pilots of the M55 Geophysica and all colleagues who made the campaigns a success.

Edited by: M. Dameris

\section{References}

Appenzeller, C. and Davies, H.: Structure of stratopheric intrusions into the troposphere, J. Geophys. Res., 101, 1435-1456, 1996.

Appenzeller, C. and Holton, J.: Seasonal variation of mass transport across the tropopause, J. Geophys. Res., 101, 15071-15078, 1996.

Baray, J.-L., Ancellet, G., Randriambelo, T., and Baldy, S.: Tropical cyclone Marlene and stratosphere-troposphere exchange, J Geophys. Res., 104, 13953-13970, 1999.

Brewer, A. W.: Evidence for a world circulation provided by the measurements of helium and water vapour distribution in the stratosphere, 75, 351-363, 1949.

Bronstein, I. N., Semendjajew, K. A., Musiol, G., and Mühlig, H.: Taschenbuch der Mathematik, Verlag Harry Deutsch, Frankfurt am Main, 1. edn., 1993.

Chen, P.: The permeability of the Antarctic vortex edge, J. Geophys. Res., 99, 20563-20571, 1994.

Chen, P.: Isentropic cross-tropopause mass exchange in the extratropics, J. Geophys. Res., 100, 16661-16673, 1995.

Curtius, J., Weigel, R., Vössing, H.-J., Wernli, H., Werner, A., Volk, C.-M., Konopka, P., Krebsbach, M., Schiller, C., Roiger, A., Schlager, H., Dreiling, V., and Borrmann, S.: Observations of meteoric material and implications for aerosol nucleation in the winter Arctic lower stratosphere derived from in situ particle measurements, Atmos. Chem. Phys., 5, 3053-3069, doi:10.5194/acp-5-3053-2005, 2005.

Danielsen, E.: Stratospheric-tropospheric exchange based on radioactivity, ozone and potential vorticity, J. Atmos. Sci, 25, 502518, 1968.

Dethof, A., O’Neill, A., and Slingo, J.: Quantification of Isentropic Mass Transport Across the Dynamical Tropopause, J. Geophys. Res., 105, 12279-12293, 2000.

Engel, A., Schiller, C., Schmidt, U., Borchers, R., Ovarlez, H., and Ovarlez, J.: The total hydrogen budget in the Arctic winter stratosphere during the European Arctic Stratospheric Ozone Experiment, J. Geophys. Res., 101, 14495-14503, 1996.

Engel, A., Bönisch, H., Brunner, D., Fischer, H., Franke, H., Günther, G., Gurk, C., Hegglin, M., Hoor, P., Königstedt, R., Krebsbach, M., Maser, R., Parchatka, U., Peter, T., Schell, D., Schiller, C., Schmidt, U., Spelten, N., Szabo, T., Weers, U., Wernli, H., Wetter, T., and Wirth, V.: Highly resolved observations of trace gases in the lowermost stratosphere and upper troposphere from the Spurt project: an overview, Atmos. Chem. Phys., 6, 283-301, doi:10.5194/acp-6-283-2006, 2006.

Ertel, H.: Ein neuer hydrodynamischer Wirbelsatz, Meteorol. Z., 59, 277-281, 1942.

ESRL, N.: GLOBALVIEW-CH4: Cooperative Atmospheric Data Integration Project - Methane, Boulder, Colorado, 2009.

EuPLEx: Final Report, Summary report, EuPLEx, Forschungszentrum Jülich, coordinator: F. Stroh, 2004.

Fischer, H., Hoor, P., and Lelieveld, J.: Seasonal Variation of Extratropical Cross-tropopause Transport Inferred from Chemical Tracer Measurements, Stratospheric Processes and their Role in Climate, SPARC-Newsletter, 2001.

Fromm, M., Tupper, A., Rosenfeld, D., Servranckx, R., and McRae, R.: Violent pyroconvective storm devastastes Australia's capital and pollutes the stratosphere, Geophys. Res. Lett., 33, L05815, doi:10.1029/2005GL025161, 2006.

Fujiwara, M., Kita, K., and Ogawa, T.: Stratosphere-troposphere 
exchange of ozone associated with equatorial Kelvin waves as observed with ozonesondes and rawinsindes, J. Geophys. Res., 103, 19173-19182, 1998.

Greenblatt, J. B., Jost, H.-J., Loewenstein, M., Podolske, J. R., Bui, P. T., Hurst, D. F., Elkins, J. W., Herman, R. L., Webster, C. R., Schauffler, S. M., Atlas, E. L., Newmann, P. A., Lait, L. R., Müller, M., Engel, A., and Schmidt, U.: Defining the polar vortex edge from an $\mathrm{N}_{2} \mathrm{O}$ :potential temperautre correlation, J. Geophys. Res., 107, 8268, doi:10.1029/2001JD000575, 2002.

Grooß, J.-U., Müller, R., Konopka, P., Steinhorst, H.-M., Engel, A., Möbius, T., and Volk, C. M.: The impact of transport across the polar vortex edge on Match ozone loss estimates, Atmos. Chem. Phys., 8, 565-578, doi:10.5194/acp-8-565-2008, 2008.

Günther, G., Müller, R., von Hobe, M., Stroh, F., Konopka, P., and Volk, C. M.: Quantification of transport across the boundary of the lower stratospheric vortex during Arctic winter 2002/2003, Atmos. Chem. Phys., 8, 3655-3670, doi:10.5194/acp-8-36552008, 2008.

Haynes, P. and Sheperd, T.: Report on the SPARC Tropopause Workshop, SPARC Newsletter 17, Stratospheric Processes And Their Role In Climate, World Climate Research Programme, Verrierres-le-Buisson, France, 2001.

Haynes, P. and Shuckburgh, E.: Effective diffusivity as a diagnostic of atmospheric transport 2. Troposphere and lower stratosphere, J. Geophys. Res., 105, 22795-22810, 2000.

Hegglin, M. I., Brunner, D., Peter, T., Hoor, P., Fischer, H., Staehelin, J., Krebsbach, M., Schiller, C., Parchatka, U., and Weers, U.: Measurements of $\mathrm{NO}, \mathrm{NO}_{\mathrm{y}}, \mathrm{N}_{2} \mathrm{O}$, and $\mathrm{O}_{3}$ during SPURT: implications for transport and chemistry in the lowermost stratosphere, Atmos. Chem. Phys., 6, 1331-1350, doi:10.5194/acp-61331-2006, 2006.

Holton, J. R., Haynes, P. H., McIntyre, M. E., Douglass, A. R., Rood, R. B., and Pfister, L.: Stratosphere-Troposphere Exchange, Rev. Geophys., 33, 403-439, 1995.

Hoor, P., Fischer, H., Lange, L., Lelieveld, J., and Brunner, D.: Seasonal Variations of a mixing layer in the lowermost stratosphere as identified by the $\mathrm{CO}-\mathrm{O}_{3}$ correlation from in-situ measurements, J. Geophys. Res., 107, 4044, doi:10.1029/2001JD000575, 2002.

Hoor, P., Gurk, C., Brunner, D., Hegglin, M. I., Wernli, H., and Fischer, H.: Seasonality and extent of extratropical TST derived from in-situ CO measurements during SPURT, Atmos. Chem. Phys., 4, 1427-1442, doi:10.5194/acp-4-1427-2004, 2004.

Hoor, P., Fischer, H., and Lelieveld, J.: Tropical and extratropical tropospheric air in the lowermost stratosphere over Europe: A CO-based budget, Geophys. Res. Lett., 32, L07802, doi:10.1029/2004GL022018, 2005.

Ivanova, E. V., Volk, C. M., Riediger, O., Klein, H., Sitnikov, N. M., Ulanovskii, A. E., Yushkov, V. A., Ravegnani, F., Möbius, T., and Schmidt, U.: A quasi-Lagrangian coordinate system based on high resolution tracer observations: implementation for the Antarctic polar vortex, Atmos. Chem. Phys. Discuss., 8, 1612316173, doi:10.5194/acpd-8-16123-2008, 2008.

Juckes, M. and McIntyre, M.: A high resolution, one-layer model of breaking planetary waves in the stratosphere, Science, 328, 590-596, 1987.

Konopka, P., Grooß, J.-U., Bausch, S., Müller, R., McKenna, D. S., Morgenstern, O., and Orsolini, Y.: Dynamics and chemistry of vortex remnants in late Arctic spring 1997 and 2000: Simu- lations with the Chemical Lagrangian Model of the Stratosphere (CLaMS), Atmos. Chem. Phys., 3, 839-849, doi:10.5194/acp-3839-2003, 2003.

Konopka, P., Steinhorst, H.-M., Grooß, J.-U., Günther, G., Müller, R., Elkins, J. W., Jost, H.-J., Richard, E., Schmidt, U., Toon, G., and McKenna, D. S.: Mixing and Ozone Loss in the 1999-2000 Arctic Vortex: Simulations with the 3-dimensional Chemical Lagrangian Model of the Stratosphere (CLaMS), J. Geophys. Res., 109, D02315, doi:10.1029/2003JD003792, 2004.

Krebsbach, M.: Trace gas transport in the UT/LS. Seasonalitiy, stratosphere - troposphere exchange and implications for the extra-tropical mixing layer derived from airborne $\mathrm{O}_{3}$ and $\mathrm{H}_{2} \mathrm{O}$ measurements, Dissertation, Universität Wuppertal, 2005.

LI-COR: LI-6251 $\mathrm{CO}_{2}$ Analyzer, Instruction Manual, LI-COR, Inc., Lincoln, Nebraska USA, 1992.

Manney, G., Zurek, R., O’Neill, A., and Swinbank, R.: On the motion of air through the stratospheric polar vortex, J. Atmos. Sci., 51, 2973-2994, 1994.

Manney, G., Santee, M., Livesey, N. J., Froidevaux, L., Read, W., Pumphrey, H.C. andWaters, J., and Pawson, S.: EOS Microwave Limb Sounder observations of the Antarctic Polar vortex break up in 2004, Geophys. Res. Lett., 32, L12811, doi:10.1029/2005GL022823, 2005.

McIntyre, M. E. and Palmer, T. N.: The 'surf zone' in the stratosphere, J. Atmos. Terr. Phys., 46, 825-849, 1984.

McKenna, D., Grooß, J.-U., Günther, G., Konopka, P., Müller, R., Carver, G., and Sasano, Y.: A new Chemical Lagrangian Model of the Stratosphere (CLaMS) 2. Formulation of chemistry scheme and intialization, J. Geophys. Res., 107, 4258, doi:10.1029/2000JD000113, 2002.

Nash, E., Newman, P., Rosenfield, J., and Schoeverl, M.: An objective determination of the polar vortex using Ertel's potential vorticity, J. Geophys. Res., 101, 9471-9478, 1996.

Newman, P. A., Fahey, D. W., Brune, W. H., and Kurylo, M. J.: Preface to special section: Photochemistry of Ozone Loss in the Arctic Region in Summer (POLARIS), J. Geophys. Res., 104, 26481-26495, 1999.

Pan, L., Solomon, S., Randel, W., Lamarque, J.-F., Hess, P., Gille, J., Chiou, E.-W., and McCormick, M. P.: Hemispheric asymetries and seasonal variations of the lowermost stratospheric water vapor and ozone derived from SAGE II data, J. Geophys. Res., 102, 28177-28184, 1997.

Plumb, R. A. and Ko, M. K. W.: Interrelations between Mixing Ratios of Long-Lived Stratospheric Constituents, J. Geophys. Res., 97, 10145-10156, 1992.

Poulida, O., Dickerson, R., and Heymsfiel, A.: Stratospheretroposphere exchange in a midlatitude mesoscale convective complex, J. Geophys. Res., 101, 6823-6836, 1996.

Press, W. H., Teukolsky, S. A., Vetterling, W. T., and Flannery, B. P.: Numerical Recipies in C, Cambridge University Press, Cambridge, 2. edn., 1992.

Ray, E. A., Moore, F. L., Elkins, J. W., Dutton, G. S., Fahey, D. W., Vmel, H., Oltmans, S. J., and Rosenlof, K. H.: Transport into the Northern Hemisphere lowermost stratosphere revealed by in situ tracer measurements, J. Geophys. Res., 104, 26565-26580, 1999.

Riediger, O.: Entwicklung und Einsatz eines flugzeuggetragenen Instrumentes zur in-situ-Messung langlebiger Spurengase in der Stratosphäre, Dissertation, Johann Wolfgang Goethe-Universität 
Frankfurt, 2000.

Rosenlof, K., Tuck, A. F., Kelly, K. K., Russell III, J. M., and McCormick, P.: Hemispheric asymmetries in water vapor and inferences bout transport in the lowermost stratosphere, J. Geophys. Res., 102, 13213-13234, 1997.

Schlager, H., Albritton, D. L., Crutzen, P. J., Goldan, P. D., Harrop, W. J., Henderson, W. R., McAfee, J. R., McFarland, M., Schiff, H. I., and Thompson, T. L.: In situ observations of air traffic signatures in the North Atlantic flight corridor, J. Geophys. Res., 102, 10739-10750, 1997.

Shapiro, M.: Turbulent mixing within tropopause folds as a mechanism for the exchange of chemical constituents between the stratosphere and troposphere, J. Atmos. Sci., 37, 994-1004, 1980.

Sokolov, L. and Lepouchov, B.: Protocol of interaction between Unit for Connection with Scientific Equipment (UCSE) and onboard scientific equipment of Geophysica aircraft (second wording), Myasishchev Design Bureau (MDB), 1998.

Sprenger, M., Maspoli, M., and Wernli, H.: Tropopause folds and cross-tropopause exchange: A global investigation based upon ECMWF analyses for the time period March 2000 to February 2001, J. Geophys. Res., 108, 8518, doi:10.1029/2002JD002587, 2003.

Stefanutti, L., Sokolov, L., Balestri, S., MacKenzie, A. R., and Khattatov, V.: The M-55 Geophysica as a Platform for the Airborne Polar Experiment, J. Atmos. Ocean. Tech., 16, 1303-1312, 1999.

Stohl, A.: A 1-year Lagrangian climatology of airstreams in the Northern Hemisphere troposphere and lowermost stratosphere, J. Geophys. Res., 106, 7263-7279, 2001.

Strunk, M.: An Experimental Study on the Mean Age of Stratospheric Air, Dissertation, Johann Wolfgang Goethe-Universität Frankfurt, 1999.

Vaughan, G. and Timmis, C.: Transport of near tropopause air into the lower mid latitude stratosphere, Q. J. Roy. Meteorol. Soc., 124, 1559-1578, 1998.
Werner, A. S.: Quantifying Transport into the Lowermost Stratosphere, Ph.D. Thesis, Goethe Universität Frankfurt, Frankfurt am Main, Germany, 2006.

Wernli, H. and Bourqui, M.: A Lagrangian "one-year climatology" of (deep) cross-tropopause exchange in the extratropical Northern Hemisphere, J. Geophys. Res., 107, 4021, doi:10.1029/2001JD000812, 2002.

Wernli, H. and Davies, H. C.: A Lagrangian-based analysis of extratropical cyclones,I; The method and some applications, Q. J. Roy. Meteorol. Soc., 123, 467-489, 1997.

Wirth, V., Appenzeller, C., and Juckes, M.: Signatures of induced vertical air motion accompanying quasi-horizontal roll-up of stratospheric intrusions, Mon. Weather Rev., 125, 2504-2519, 1997.

WMO: Scientific assessment of ozone depletion: 2006, Global Ozone Research and Monitoring Project - Report No. 50, World Meteorological Organization, Geneva, Switzerland, 2007.

Zachariasse, M., Smit, H., van Velthoven, P., and Kelder, H.: Cross tropopause and interhemispheric transports into the tropical free troposphere over the Indian Ocean, J. Geophys. Res., 106, 28441-28452, 2001.

Zierl, B. and Wirth, V.: The role of radiation for stratospheretroposphere exchange in an upper tropospheric anitcyclone, J. Geophys. Res., 102, 23883-23894, 1997.

Zöger, M., Afchine, A., Eicke, N., Gerhards, M.-T., Klein, E., McKenna, D. S., Mörschel, U., Schmidt, U., Tan, V., Tuitjer, F., Woyke, T., and Schiller, C.: Fast in situ stratospheric hygrometers: A new family of balloon-borne and airborne Lyman- $\alpha$ photofragment fluorescence hygrometers, J. Geophys. Res., 104, 1807-1816, 1999. 